\title{
Molecular Targeting of the Oncoprotein PLK1 in Pediatric Acute Myeloid Leukemia: RO3280, a Novel PLK1 Inhibitor, Induces Apoptosis in Leukemia Cells
}

Na-Na Wang ${ }^{1, \dagger}$, Zhi-Heng Li ${ }^{1, \dagger}$, He Zhao ${ }^{1, \dagger}$, Yan-Fang Tao ${ }^{1}$, Li-Xiao Xu ${ }^{1}$, Jun Lu ${ }^{1}$, Lan Cao ${ }^{1}$, Xiao-Juan Du ${ }^{2}$, Li-Chao Sun ${ }^{3}$, Wen-Li Zhao ${ }^{1}$, Pei-Fang Xiao ${ }^{1}$, Fang Fang ${ }^{1}$, Guang-Hao Su ${ }^{1}$, Yan-Hong Li ${ }^{1}$, Gang Li ${ }^{1}$, Yi-Ping Li ${ }^{1}$, Yun-Yun Xu ${ }^{1}$, Hui-Ting Zhou ${ }^{1}$, Yi Wu ${ }^{1}$, Mei-Fang Jin ${ }^{1}$, Lin Liu ${ }^{1}$, Jian $\mathrm{Ni}^{4}$, Jian Wang ${ }^{1}$, Shao-Yan Hu ${ }^{1}$, Xue-Ming Zhu ${ }^{1}$, Xing Feng ${ }^{1, *}$ and Jian Pan ${ }^{1, *}$

1 Department of Hematology and Oncology, Children's Hospital of Soochow University, Suzhou 215003, China; E-Mails: wangnn90s@163.com (N.-N.W.);

szlizhiheng@hotmail.com (Z.-H.L.); zhaoheytr@163.com (H.Z.); taoyanfang1982@163.com (Y.-F.T.); xulixiao2013@hotmail.com (L.-X.X.); drlujun_sz@163.com (J.L.); cl2012@sohu.com (L.C.); wenlizhao69@163.com(W.-L.Z.); xiaopfdr@gmail.com (P.-F.X.); baseff77@gmail.com (F.F.); sky2skeleton@163.com (G.-H.S.); lyh072006@hotmail.com (Y.-H.L.); ligangmailbox@hotmail.com (G.L.); ray8302880@163.com (Y.-P.L.); rdxyy@163.com (Y.-Y.X.); huitingzhousdfey@163.com (H.-T.Z.); conan.005@stu.xjtu.edu.cn (Y.W.); sunnysnow12@163.com (M.-F.J.); flykf@163.com (L.L.); wj196312@vip.163.com (J.W.); hsy139@126.com (S.-Y.H.); xueming_zhu@aliyun.com (X.-M.Z.)

2 Department of Gastroenterology, the 5th Hospital of Chinese People's Liberation Army (PLA), Yinchuan 750000, China; E-Mail: du_xiaojuan123@163.com

3 Department of Cell and Molecular Biology, Cancer Institute (Hospital), Chinese Academy of Medical Sciences, Peking Union Medical College, Beijing 100021, China; E-Mail: sunlichao_1980@hotmail.com

4 Translational Research Center, Second Hospital, The Second Clinical School, Nanjing Medical University, Nanjing 210000, China; E-Mail: ni_jian2008@163.com

$\dagger$ These authors contributed equally to this work.

* Authors to whom correspondence should be addressed;

E-Mails: panjian2008@163.com (J.P.); xing_feng66@hotmail.com (X.F.); Tel./Fax: +86-512-6778-6601 (J.P.); +86-512-6778-8216 (X.F.).

Academic Editor: William Chi-shing Cho 


\begin{abstract}
Polo-like kinase 1 (PLK1) is highly expressed in many cancers and therefore a biomarker of transformation and potential target for the development of cancer-specific small molecule drugs. RO3280 was recently identified as a novel PLK1 inhibitor; however its therapeutic effects in leukemia treatment are still unknown. We found that the PLK1 protein was highly expressed in leukemia cell lines as well as 73.3\% (11/15) of pediatric acute myeloid leukemia (AML) samples. PLK1 mRNA expression was significantly higher in AML samples compared with control samples $(82.95 \pm 110.28$ vs. $6.36 \pm 6.35$; $p<0.001)$. Kaplan-Meier survival analysis revealed that shorter survival time correlated with high tumor PLK1 expression $(p=0.002)$. The 50\% inhibitory concentration ( $\left.\mathrm{IC}_{50}\right)$ of RO3280 for acute leukemia cells was between 74 and $797 \mathrm{nM}$. The $\mathrm{IC}_{50}$ of RO3280 in primary acute lymphocytic leukemia (ALL) and AML cells was between 35.49 and $110.76 \mathrm{nM}$ and 52.80 and $147.50 \mathrm{nM}$, respectively. RO3280 induced apoptosis and cell cycle disorder in leukemia cells. RO3280 treatment regulated several apoptosis-associated genes. The regulation of DCC, CDKN1A, BTK, and SOCS2 was verified by western blot. These results provide insights into the potential use of RO3280 for AML therapy; however, the underlying mechanisms remain to be determined.
\end{abstract}

Keywords: RO3280; pediatric acute myeloid leukemia (AML); polo-like kinase 1 (PLK1); apoptosis; oncogene target

\title{
1. Introduction
}

Acute leukemia is a family of serious medical conditions relating with an original diagnosis of leukemia. Acute leukemia is known as cancer of the blood which can cause death if not medicated [1]. Multiple small-molecule kinase inhibitors are currently being developed for leukemia treatment [2-5]. For example, selective FLT3 (fms-related tyrosine kinase 3) inhibitors, such as AC220 (quizartinib), have been proven clinically effective in acute myeloid leukemia (AML) patients with internal tandem duplications (ITD) in the gene of FLT3 [6,7]. Other inhibitors in development target mediators of downstream signaling pathways, such as mTOR [8] and MEK [9], or cell cycle machinery, such as aurora kinases [3,10] or cyclin-dependent kinases [11]. Recently, the polo-like kinase 1 (PLK1) inhibitor has showed promising effects in the treatment of acute leukemia. Polo-like kinases (PLKs) are a set of regulators that control mitotic progression [12]. PLK1, the best-characterized mammalian PLK, is a particularly attractive target for cancer drug development because most cancers require its activity [12-15].

PLK1 is a serine/threonine-protein kinase expressed during mitosis and overexpressed in multiple cancers, including acute leukemia [13]. PLK1 expression is increased in several types of cancers including urothelial carcinoma of bladder [16], renal cancer [17], breast cancer [18], prostate cancer [19], neuroblastoma [20], hepatocellular carcinoma [21], cervical carcinoma [22], and non-melanoma skin 
cancers [23]. PLK1 is also highly expressed in leukemic cell lines and over expressed in a majority of samples from patients with acute myeloid leukemia compared with normal progenitors [24]. And PLK1 knockdown by small interfering RNA also blocked proliferation of leukemic cell lines and the clonogenic potential of primary cells from patients [24]. PLK1 inhibition is a promising strategy for the treatment of AML. Furthermore, the expression of PLK1 in untransformed cells is much lower, which makes PLK1 a suitable target for the development of cancer-specific small molecule drugs. Supporting evidence of oncogenic properties of PLK1 comes from the overexpression studies of PLK1 in an NIH3T3 cell line $[25,26]$. These cells become capable of forming foci in soft agar due to PLK1 overexpression [27]. Depletion or inhibition of kinase activity of PLK1 is sufficient to induce cell-cycle arrest and apoptosis in cancer cell lines and in xenograft tumor models [28-31].

Inhibitors of PLK1 have been developed for potential human cancer therapy. NMS-P937 is a novel PLK1-specific inhibitor and shows high potency in proliferation inhibition on a large number of cell lines [28]. Another PLK1 inhibitor, BI2536, was tested against a panel of nine ALL cell lines at nanomolar concentrations. BI2536 strongly diminished colony formation capacity and increased apoptosis rates of these cells [32]. Co-treatment with BI2536 and vorinostat synergistically induced cell death in parental or imatinib mesylate-resistant BCR/ABL+ cells and primary CD34+ bone marrow cells but was minimally toxic to normal cells [33]. TAK-960 is another novel PLK1 inhibitor that has shown activity in several tumor cell lines, including those cells highly expressed multidrug-resistant protein 1 (MDR1) [29]. GW843682X is also a novel selective PLK1 inhibitor which caused accumulation of cells in the $\mathrm{G}_{2} / \mathrm{M}$ phase and mediated apoptosis of human leukemia cells [34].

Wovkulich and colleagues [30] have developed a novel PLK1 inhibitor, RO3280; RO3280 has potent inhibitory activity against PLK1, good selectivity against other kinases, and excellent in vitro cellular potency. However, the molecular function of this drug in leukemia is still unknown [30]. In the present study, RO3280 has been evaluated to further characterize its preclinical antitumor efficacy, and the molecular mechanism of action was explored with real-time PCR arrays.

\section{Results and Discussion}

\subsection{Expression of PLK1 Is Upregulated in AML Cells and Pediatric AML Patients}

As reported previously, PLK1 is highly expressed in a broad set of cancer cell lines and overexpressed in a majority of cancer patient samples compared with normal progenitor cells. However, the expression of PLK1 in AML, and specifically pediatric AML, has not been clearly defined. We demonstrate that the expression of PLK1 is very high in AML cell lines, with the highest levels observed in CCRF, NB4, and K562 cells (Figure 1A). To examine the expression of PLK1 in pediatric AML samples, we obtained samples from 15 patients with pediatric AML and 12 control patients. High protein expression of PLK1 was observed in $73.3 \%(11 / 15)$ of the pediatric AML samples compared to $0 \%(0 / 12)$ of the normal bone marrow (NBM) control samples (Figure 1B). Real-time PCR was also used to examine the mRNA transcript levels of PLK1 in 105 pediatric AML samples and $30 \mathrm{NBM} / \mathrm{ITP}$ (idiopathic thrombocytopenic purpura) (control samples (Figure 1C)). PLK1 expression was significantly higher in the AML samples compared to the control samples 
$(82.95 \pm 110.28 v$ vs. $6.36 \pm 6.35 ; p<0.001)$. Bone marrow specimens were obtained from 105 pediatric patients with AML at the time of diagnosis, who presented at Children's Hospital of Soochow University between 2000 and 2011. We suppose the high SD (standard deviation) values are related to the cDNA quality of samples. Examination of pediatric AML patient clinicopathology revealed that expression of PLK1 is related with FAB (French-American-Britain) and MRD (Minimal Residual Disease, Table 1). However, there were no significant differences in other clinical features such as sex, age, initial hemoglobin level, white blood cell counts, platelet counts, or chromosomal abnormalities between individuals with high and low PLK1 expression (Table 1). The prognostic significance of PLK1 expression was assessed in 105 Chinese pediatric AML patients with clinical follow-up records. Kaplan-Meier survival analysis revealed shorter survival times for patients with high PLK1 expression in tumors ( $p=0.002$, Table 2 and Figure 1C). Furthermore, multivariate analysis revealed that PLK1 expression is an independent prognostic factor in pediatric AML $(p=0.041$, Table 3$)$. In summary, our results demonstrate that PLK1 expression is heightened in patients with pediatric AML and in human myeloid leukemia cell lines. This indicates that PLK1 may be a suitable oncogene target for pediatric AML therapy.

A

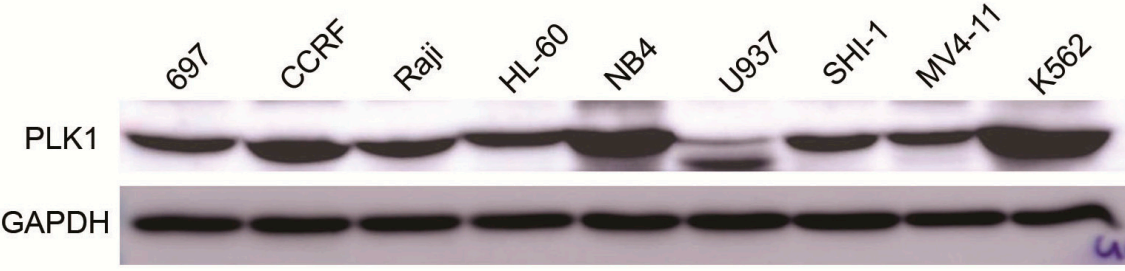

B
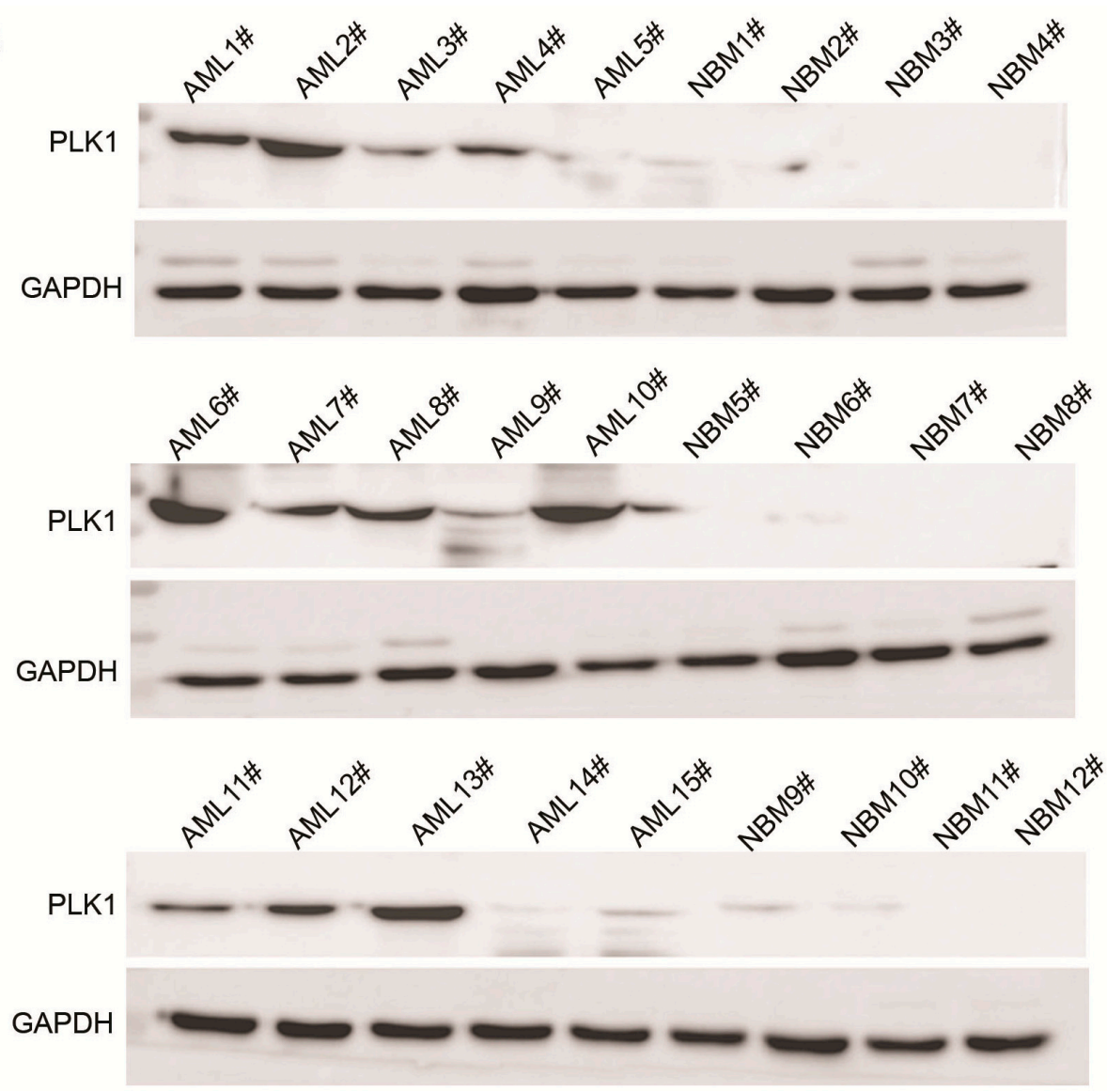

Figure 1. Cont. 

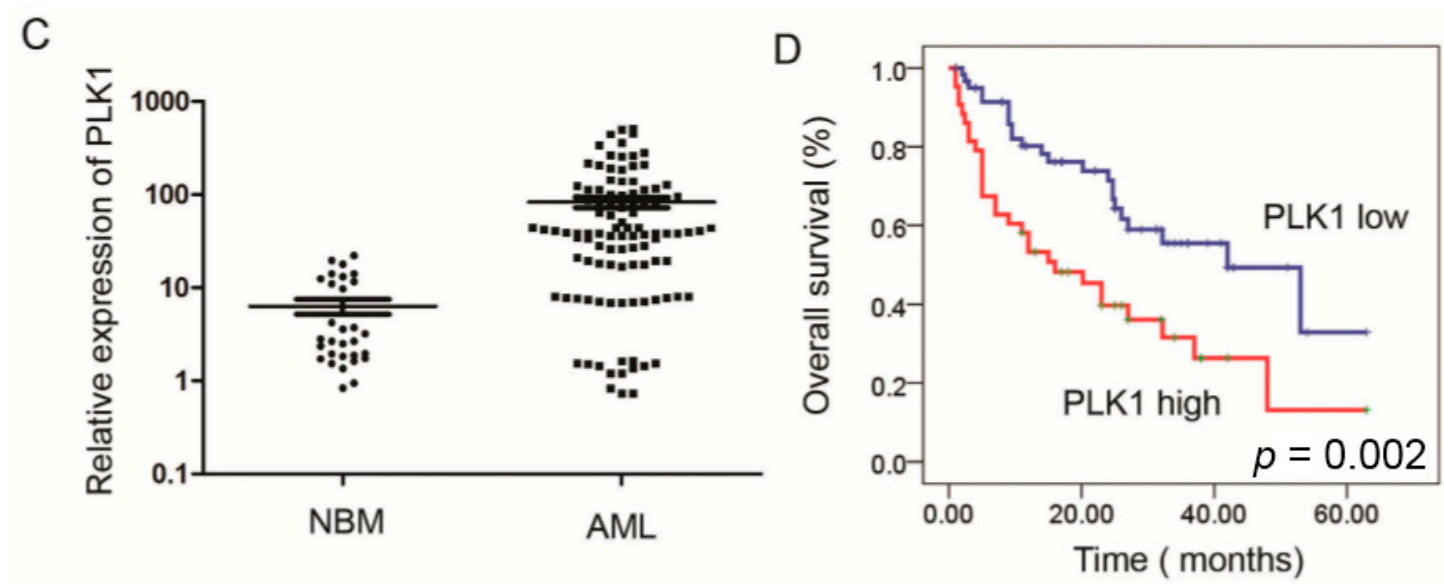

Figure 1. Expression of PLK1 is upregulated in AML cells and pediatric AML patients (A) Western blot analysis showing PLK1 protein expression in nine leukemia cell lines; (B) Western blot analysis showing PLK1 protein expression in 15 pediatric AML samples and 12 NBM samples; (C) Real-time PCR analysis of the PLK1 mRNA transcript levels in 105 pediatric AML samples and $30 \mathrm{NBM} / \mathrm{ITP}$ (normal bone marrow/idiopathic thrombocytopenic purpura) control samples; and (D) Kaplan-Meier survival analysis of 105 pediatric AML patients comparing high and low PLK1 expression $(p=0.002)$.

Table 1. Association of polo-like kinase 1 (PLK1) expression with clinico-pathological characteristics in 105 pediatric acute myeloid leukemia (AML) samples.

\begin{tabular}{|c|c|c|c|c|}
\hline \multirow{2}{*}{ Clinical Variables } & \multirow{2}{*}{ No. of Patients } & \multicolumn{2}{|c|}{ PLK1 Expression (n) } & \multirow{2}{*}{$p$} \\
\hline & & Low & High & \\
\hline \multicolumn{5}{|l|}{ Gender } \\
\hline Male & 42 & 27 & 15 & \multirow{2}{*}{0.373} \\
\hline Female & 63 & 35 & 28 & \\
\hline \multicolumn{5}{|l|}{ Age (year) } \\
\hline$<6$ & 60 & 35 & 25 & \multirow{2}{*}{0.864} \\
\hline$\geq 6$ & 45 & 27 & 18 & \\
\hline \multicolumn{5}{|l|}{ Leukocyte $(/ \mu \mathrm{L})$} \\
\hline$>10,000$ & 61 & 37 & 24 & \multirow{2}{*}{0.693} \\
\hline$\leq 10,000$ & 44 & 25 & 19 & \\
\hline \multicolumn{5}{|l|}{ FAB } \\
\hline M1-M6 & 93 & 59 & 34 & \multirow{2}{*}{0.011} \\
\hline M7 & 12 & 3 & 9 & \\
\hline \multicolumn{5}{|l|}{ Cytogenetics } \\
\hline Favorable & 50 & 28 & 22 & \multirow{3}{*}{0.160} \\
\hline Intermediate & 27 & 20 & 7 & \\
\hline Unfavorable & 28 & 14 & 14 & \\
\hline \multicolumn{5}{|l|}{ MRD } \\
\hline$<0.25 \%$ & 49 & 36 & 13 & \multirow{2}{*}{0.005} \\
\hline$\geq 0.25 \%$ & 56 & 26 & 30 & \\
\hline
\end{tabular}

FAB: French-American-Britain; MRD: Minimal Residual Disease. 
Table 2. Association of PLK1 expression with Kaplan-Meier survival in 105 pediatric AML samples.

\begin{tabular}{cccc}
\hline Variable & \multirow{2}{*}{ No. of Patients } & $\begin{array}{c}\text { Over Survival } \\
\end{array}$ & \multirow{2}{*}{$\boldsymbol{p}$} \\
\hline Cytogenetics & & & \\
Favorable & 50 & $46.664 \pm 3.717$ & \\
Intermediate & 27 & $29.220 \pm 3.188$ & $<0.001$ \\
Unfavorable & 28 & $11.161 \pm 1.827$ & \\
\hline FAB & & & \\
M1-M6 & 93 & $36.113 \pm 2.885$ & $<0.001$ \\
M7 & 12 & $8.542 \pm 1.820$ & \\
\hline Leukocyte $(/ \mu \mathrm{L})$ & & & \\
$>10,000$ & 61 & $30.220 \pm 2.974$ & \multirow{2}{*}{0.803} \\
$\leq 10,000$ & 44 & $33.631 \pm 4.063$ & \\
\hline MRD & & & \\
$<0.25 \%$ & 49 & $53.627 \pm 3.151$ & $<0.001$ \\
$\geq 0.25 \%$ & 56 & $18.893 \pm 2.425$ & \\
\hline PLK1 expression & & & \\
Low $(<12.420)$ & 62 & $39.319 \pm 3.539$ & 0.002 \\
High $(\geq 12.420)$ & 43 & $24.054 \pm 3.709$ & \\
\hline
\end{tabular}

Table 3. Cox multivariate analysis of PLK1 expression and clinico-pathological features in pediatric AML.

\begin{tabular}{cccc}
\hline Variable & Odds Ratio & EXP (B) 95\% CI & $\boldsymbol{p}$ \\
\hline $\begin{array}{c}\text { Cytogenetics } \\
\text { Favorable } v s . \text { Intermediate and Unfavorable }\end{array}$ & 6.164 & $2.477(1.210-5.068)$ & 0.013 \\
\hline $\begin{array}{c}\text { MRD } \\
<0.25 \% \text { vs. } \geq 0.25 \%\end{array}$ & 14.084 & $5.176(2.193-12.214)$ & 0.000 \\
\hline $\begin{array}{c}\text { Leukocyte }(/ \mathrm{uL}) \\
>10,000 v s . \leq 10,000\end{array}$ & 0.200 & $1.138(0.646-2.055)$ & 0.655 \\
\hline $\begin{array}{c}\text { FAB classification } \\
\text { M7 vs. M1-M6 }\end{array}$ & 7.148 & $2.683(1.301-5.533)$ & 0.008 \\
\hline $\begin{array}{c}\text { PLK1 Expression } \\
\text { Low } v s . \text { High }\end{array}$ & 4.195 & $1.806(1.026-3.179)$ & 0.041 \\
\hline
\end{tabular}

EXP (B) $95 \%$ CI: 95\% CI (confidence intervals) of relative risk.

\subsection{RO3280 Inhibits the Growth of Acute Leukemia Cells}

The novel PLK1 inhibitor RO3280 decreased leukemia cell viability in a dose-dependent manner (Figure 2A,B). The RO3280 IC50 measurement was determined in several acute leukemia cell lines: U937 186 nM, HL60 175 nM, NB4 74 nM, K562 797 nM, MV4-11 120 nM, and CCRF 162 nM. RO3280 treatment could also dramatically impact cell morphology as observed in NB4 cells (Figure 2C).

In order to better understand the effective of RO3280, we compared it with other PLK1 inhibitors: Rigosertib (ON 01910. Na) and BI2536. The IC 50 of these PLK1 inhibitors was analyzed in both NB4 and K562 cells (Figure 2D). In NB4 cells the following $\mathrm{IC}_{50}$ concentrations were determined: RO3280 $13.45 \mathrm{nM}$, ON 01910. Na $13.02 \mathrm{nM}$, and BI2536 $87.65 \mathrm{nM}$. In K562 cells the following IC50 concentrations 
were determined: RO3280 $301 \mathrm{nM}$, ON 01910. Na $1606 \mathrm{nM}$, and BI2536 $448 \mathrm{nM}$. To determine the effectiveness of RO3280 in primary leukemia, we determined the IC50 in ALL and AML cells. In primary ALL the IC50 of RO3280 is $35.49-110.76 \mathrm{nM}$ (Figure 2E, Table 4) and in primary AML the IC50 of RO3280 is $52.80-147.50 \mathrm{nM}$ (Figure 2E, Table 5). These results demonstrate that the PLK1 inhibitor RO3280 effectively inhibits the proliferation of leukemia cells.

\subsection{RO3280 Induced Apoptosis and Cell Cycle Disorder in Leukemia Cells}

To determine if RO3280 induces apoptosis in leukemia cells, we assessed Annexin V staining, cell cycle disorder and caspase activation in leukemia cells after treatment. Cells treated with RO3280 for $24 \mathrm{~h}$ showed higher Annexin V staining compared with untreated cells (Figure 3). This indicates that RO3280 induces apoptosis in leukemia cells. Cell cycle disorder was determined by a cell cycle assay, which showed that RO3280 significantly induces cell cycle disorder in nine leukemia cell lines (Figure 4). Hoechst 33342 staining showed that $24 \mathrm{~h}$ RO3280 treatment induced DNA fragmentation and the formation of abnormal nuclear cells (Figure 5A). When either HL-60 or NB4 cells were treated with RO3280, there was a significant increase in abnormal nuclear cell formation compared with control DMSO treated cells (Figure 5B). Moreover, to clearly demonstrate that RO3280 causes apoptosis in leukemia cells, we assessed the following well-recognized markers of apoptosis: PARP, caspase-3, and caspase-9. After $24 \mathrm{~h}$ of treatment with RO3280 (50 or $100 \mathrm{nM}$ ), cleaved PARP and caspase-9 were observed in NB4 and HL-60 cells (Figure 5C). These results are consistent with the Annexin V staining and cell cycle analysis, demonstrating that RO3280 induces apoptosis in leukemia cells. This further suggests that RO3280 may have promising antitumor therapeutic applications.

A<smiles>COc1cc(C(=O)NC2CCN(C)CC2)ccc1Nc1ncc2c(n1)N(C1CCCC1)CC(F)(F)C2=O</smiles>

RO3280 MW: 543.61

C

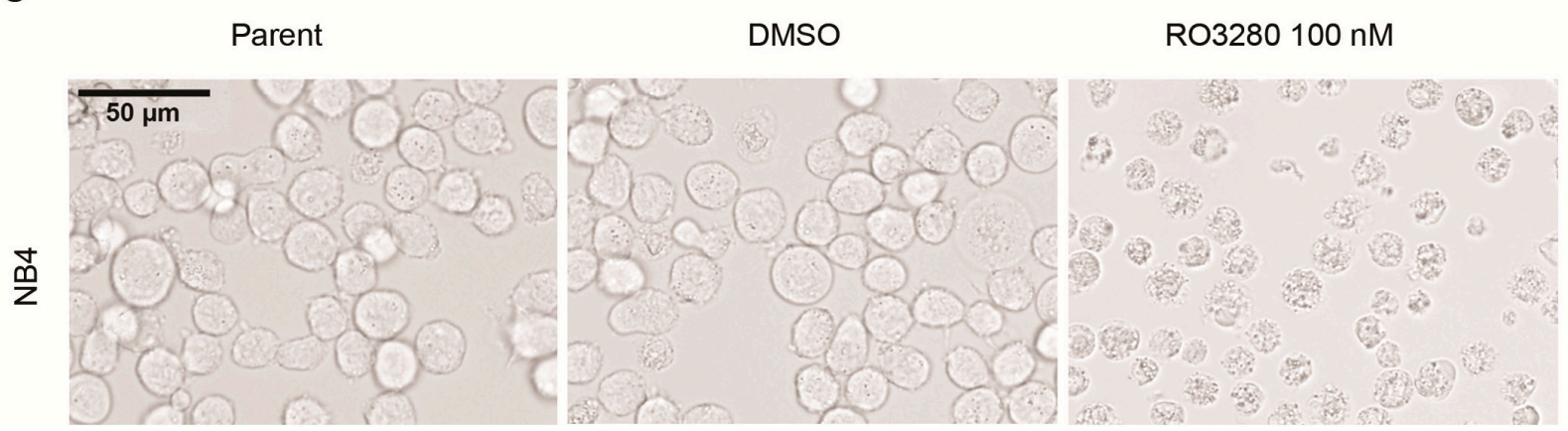

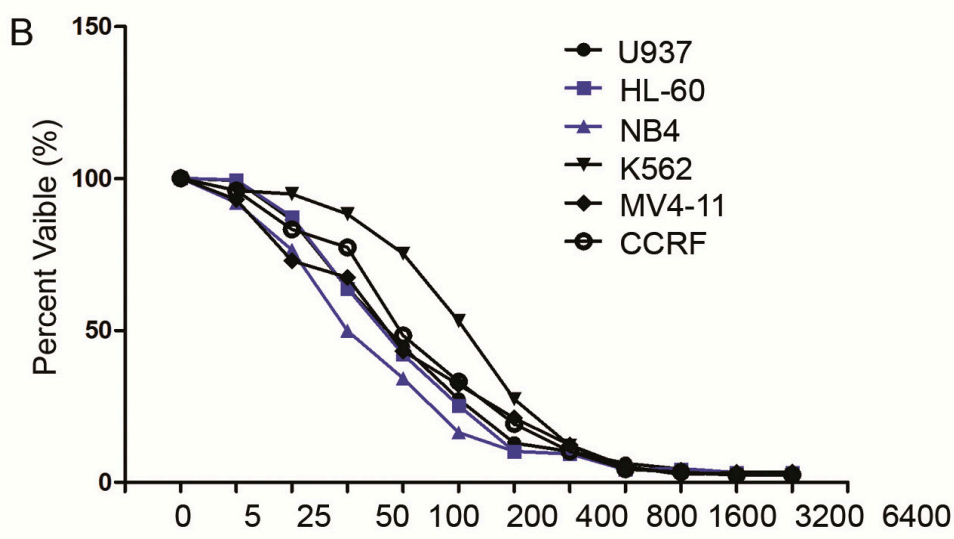

DMSO 
D

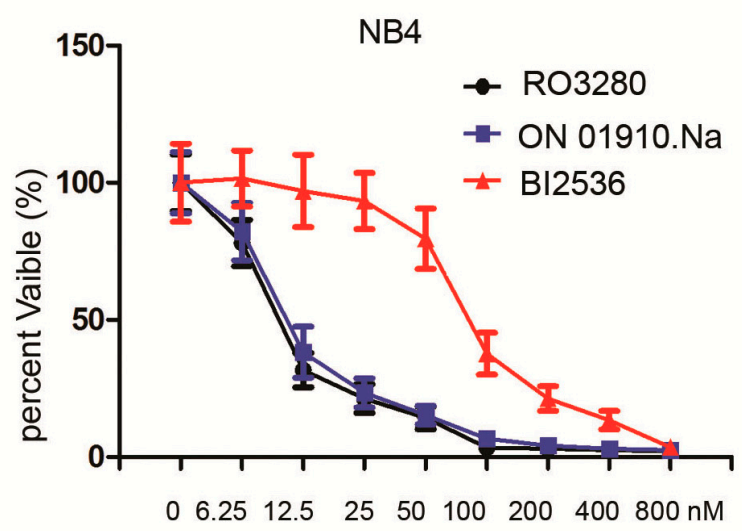

Primary pediatric ALL

$E$

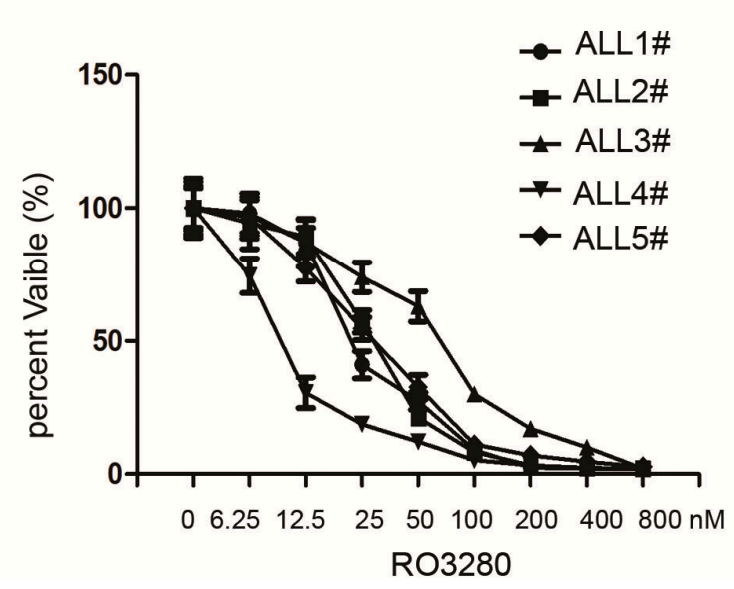

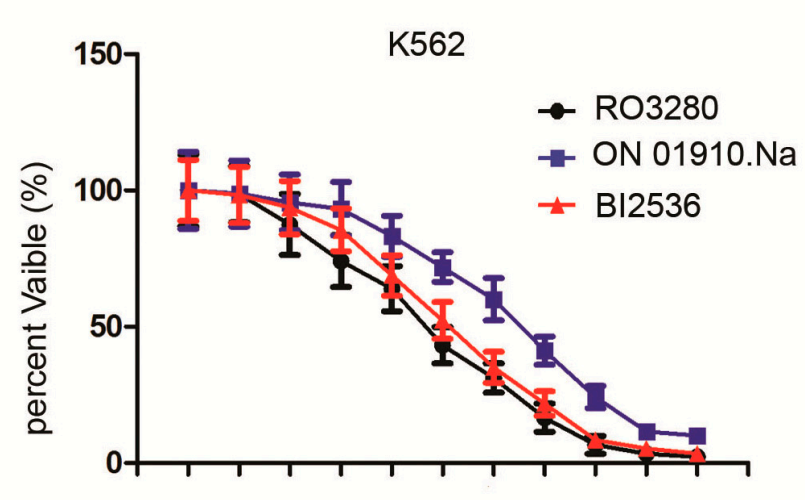

$06.2512 .52510040016003200640012800 \mathrm{nM}$ Primary pediatric AML

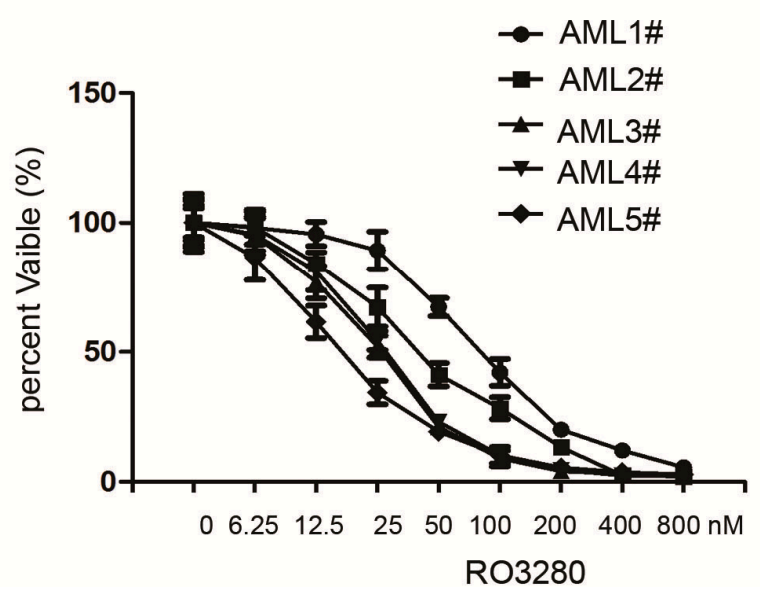

Figure 2. RO3280 inhibits the growth of acute leukemia cells. (A) Molecular structure of RO3280; (B) Viability and $\mathrm{IC}_{50}$ analysis of RO3280 in six leukemia cells. The following are the determined RO3280 IC50s: U937 186 nM, HL60 175 nM, NB4 74 nM, K562 $797 \mathrm{nM}$, MV4-11 $120 \mathrm{nM}$ and CCRF $162 \mathrm{nM}$; (C) Micrographs were taken of NB4 cells treated with RO3280 $100 \mathrm{nM}$ or DMSO (scale bar $=50 \mu \mathrm{m}$ ); (D) The IC 50 of three PLK1 inhibitors, RO3280, ON 01910.Na and BI2536, was analyzed in NB4 and K562 cells. IC 50 in NB4 cells: RO3280 $13.45 \mathrm{nM}$, ON 01910. Na $13.02 \mathrm{nM}$, and BI2536 $87.65 \mathrm{nM}$. IC50 in K562 cells: RO3280 301 nM, ON 01910. Na 1606 nM, and BI2536 is 448 nM; and (E) The $\mathrm{IC}_{50}$ of RO3280 in primary acute lymphocytic leukemia (ALL) and AML cells was also analyzed: ALL 35.49-110.76 $\mathrm{nM}$ and AML 52.80-147.50 nM. Cell proliferation was calculated as a percentage of the DMSO treated control wells. The $\mathrm{IC}_{50}$ values were derived after plotting proliferation values on a logarithmic curve. Experiments were performed in quadruplicate and repeated twice. 
Table 4. Pathologic features and inhibition of cell growth by RO3280 in primary culture cells of pediatric ALL.

\begin{tabular}{|c|c|c|c|c|c|c|c|c|c|}
\hline Number & Gender & Age (Years) & Diagnosis & $\begin{array}{l}\text { ALL } \\
\text { Typing }\end{array}$ & Chromosome Analysis & Fusion Gene & Prednisone Sensitivity & PLK1 & $\mathrm{IC}_{50}(\mathrm{nM})$ \\
\hline 1 & Female & 5 & ALL & $\mathrm{B}$ & $46, X Y$ & Not detected & Sensitive & positive & 35.39 \\
\hline 2 & Male & 4 & ALL & B & $46, X Y$ & $T E L / A M L 1^{+}$ & Sensitive & positive & 30.79 \\
\hline 3 & Male & 3 & ALL & B & $\begin{array}{l}\text { ALL/53-54, XY, }+4,+6,+10 \\
12 p^{+},+14,+17,+18,+20,+21\end{array}$ & Not detected & Sensitive & positive & 64.43 \\
\hline 4 & Female & 4 & ALL & B & $46, \mathrm{XX}$ & Not detected & Sensitive & positive & 8.27 \\
\hline 5 & Female & 4 & ALL & B & $\begin{array}{c}\text { ALL/53-55, XX, }+\mathrm{X}, 1 \mathrm{q}+,+4 \\
+6,+10,+11,+15,+17,+21\end{array}$ & Not detected & Sensitive & positive & 36.01 \\
\hline
\end{tabular}

Table 5. Pathologic features and inhibition of cell growth by RO3280 in primary culture cells of pediatric AML.

\begin{tabular}{ccccccccc}
\hline Number & Gender & Age (Years) & Diagnosis & AML Typing & Chromosome Analysis & Fusion Gene & PLK1 & IC 5 nM \\
\hline 1 & Female & 9 & AML & M4 & 46, XX & FLT3-ITD & positive & 88.65 \\
2 & Female & 3 & AML & M4 & $46, \mathrm{XX}$, inv $(16)(\mathrm{p} 13 ; \mathrm{q} 22)$ & $C B F / M Y H 11$ & positive & 47.02 \\
3 & Male & 4 & AML & M5b & $46, \mathrm{XY},-2,+10, \mathrm{t}(10 ; 10)(\mathrm{p} 13 ; \mathrm{q} 23)$ & $M L L / A F 10$ & positive & 28.57 \\
4 & Male & 12 & AML & M2a & $45, \mathrm{X},-\mathrm{Y}, \mathrm{t}(8 ; 21)(\mathrm{q} 22 ; \mathrm{q} 22)$ & $A M L / E T O$ & positive & 32.92 \\
5 & Female & 1 & AML & M4 & $46, \mathrm{XX}$, inv $(16)(\mathrm{p} 13 ; \mathrm{q} 22)$ & Not detected & positive & 19.20 \\
\hline
\end{tabular}



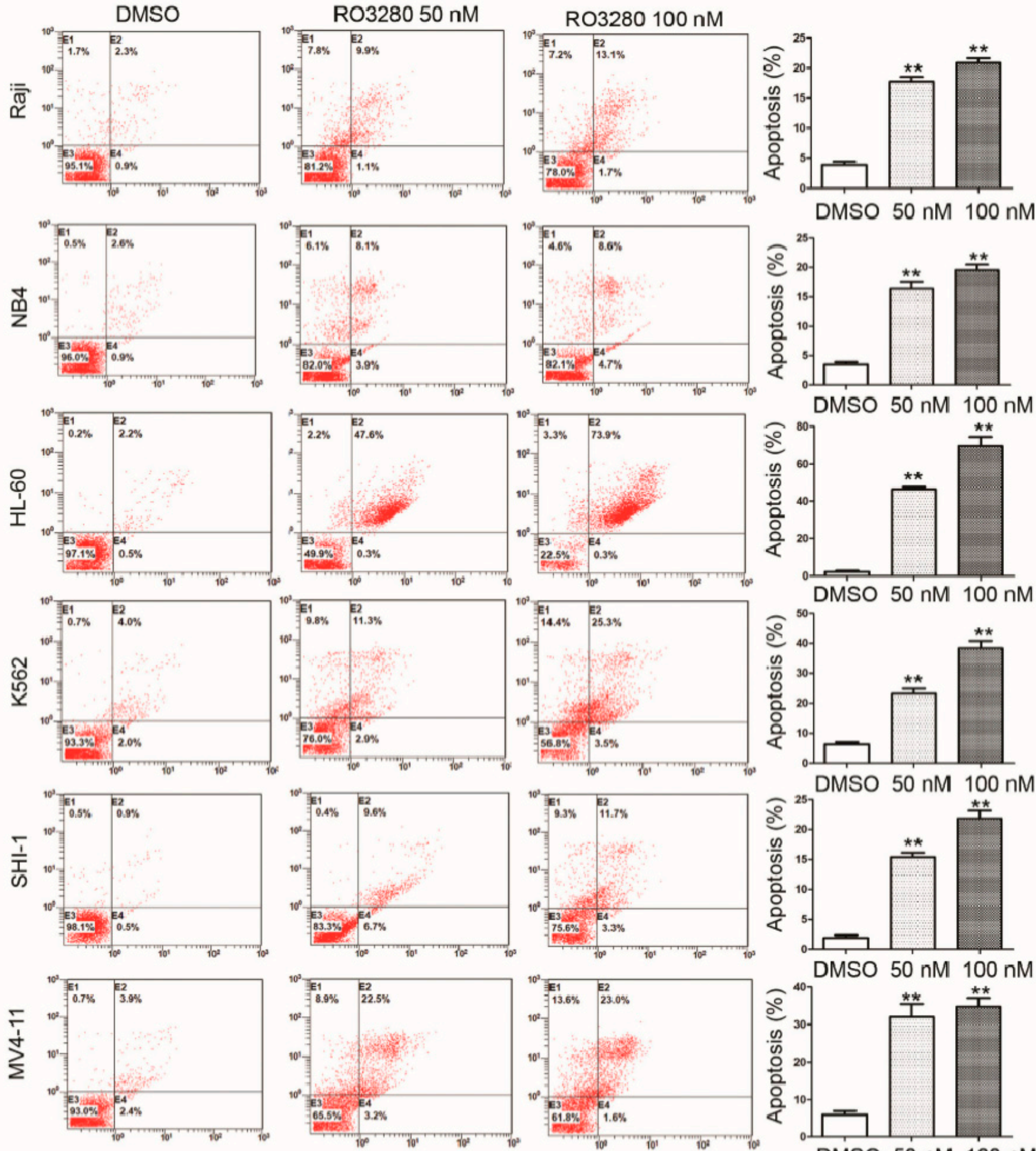

DMSO 50 nM 100 nM
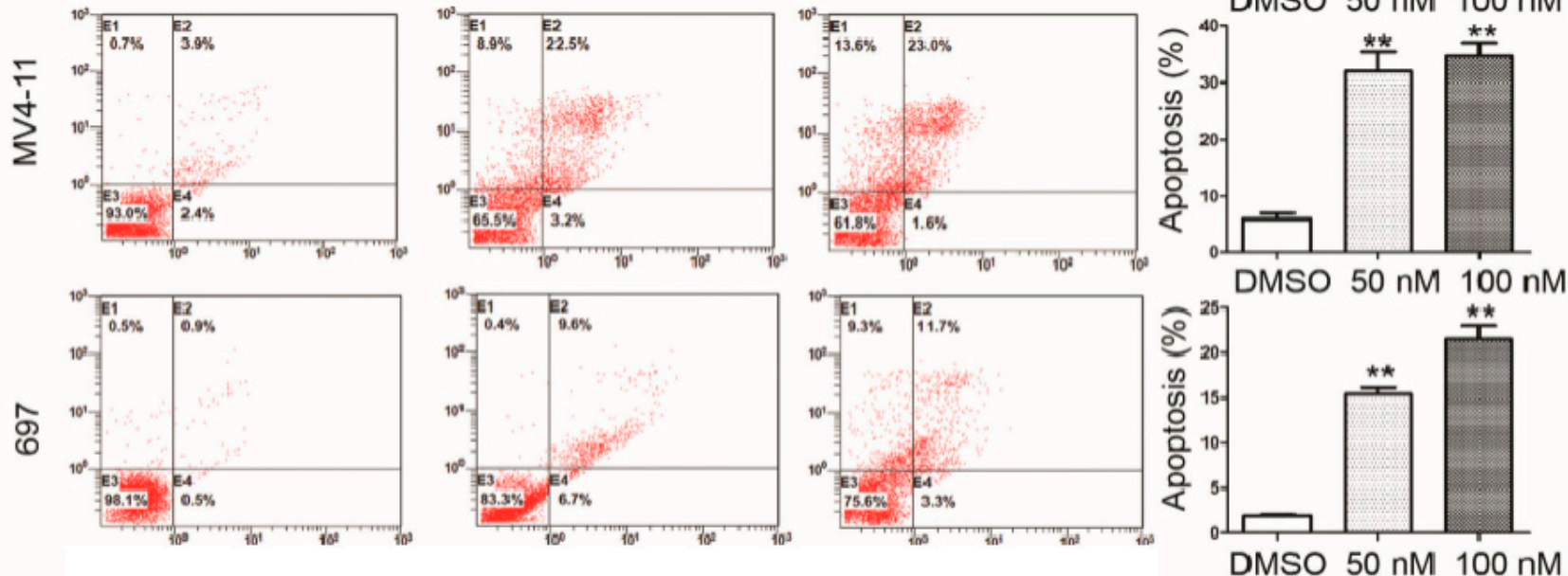

Figure 3. Cont. 

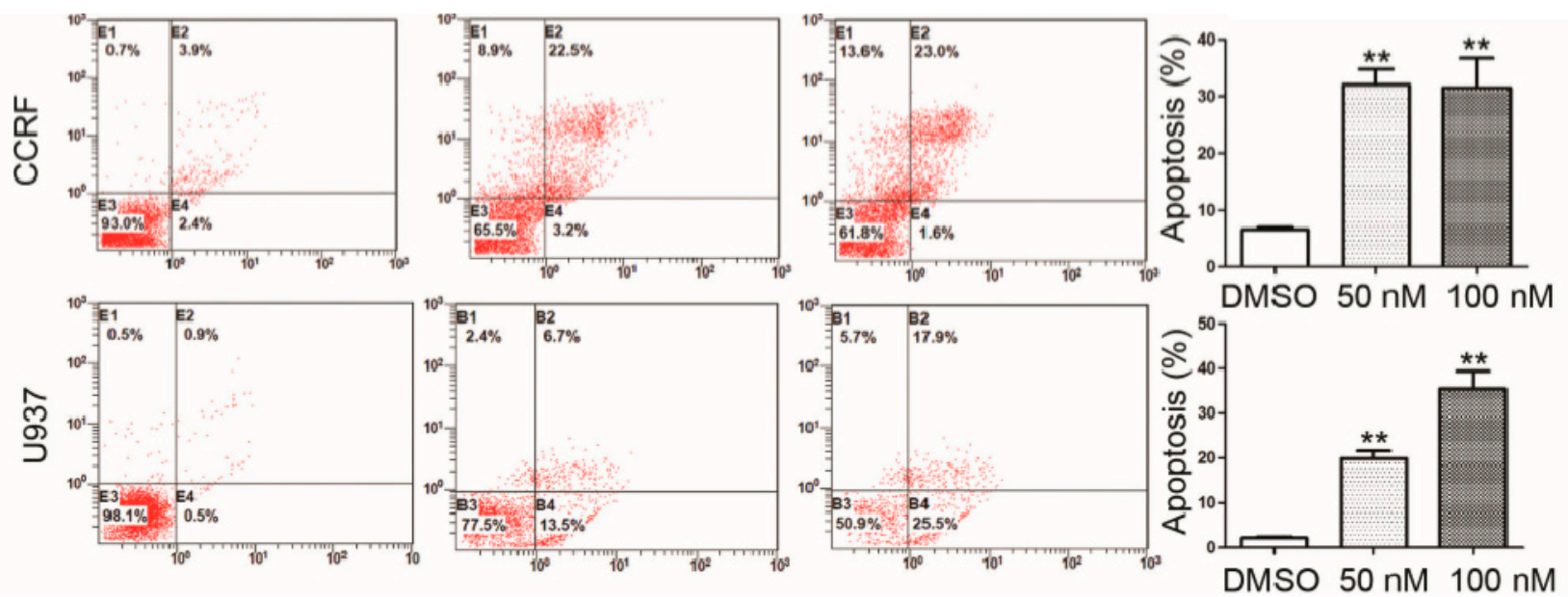

Figure 3. Annexin V analysis of apoptosis induced by RO3280 in acute leukemia cells. Annexin V staining of cells following a $24 \mathrm{~h}$ treatment with RO3280 at 50 or $100 \mathrm{nM}$ compared with DMSO control mock treatment. All these analyses were repeated three times. $* * p<0.01$.

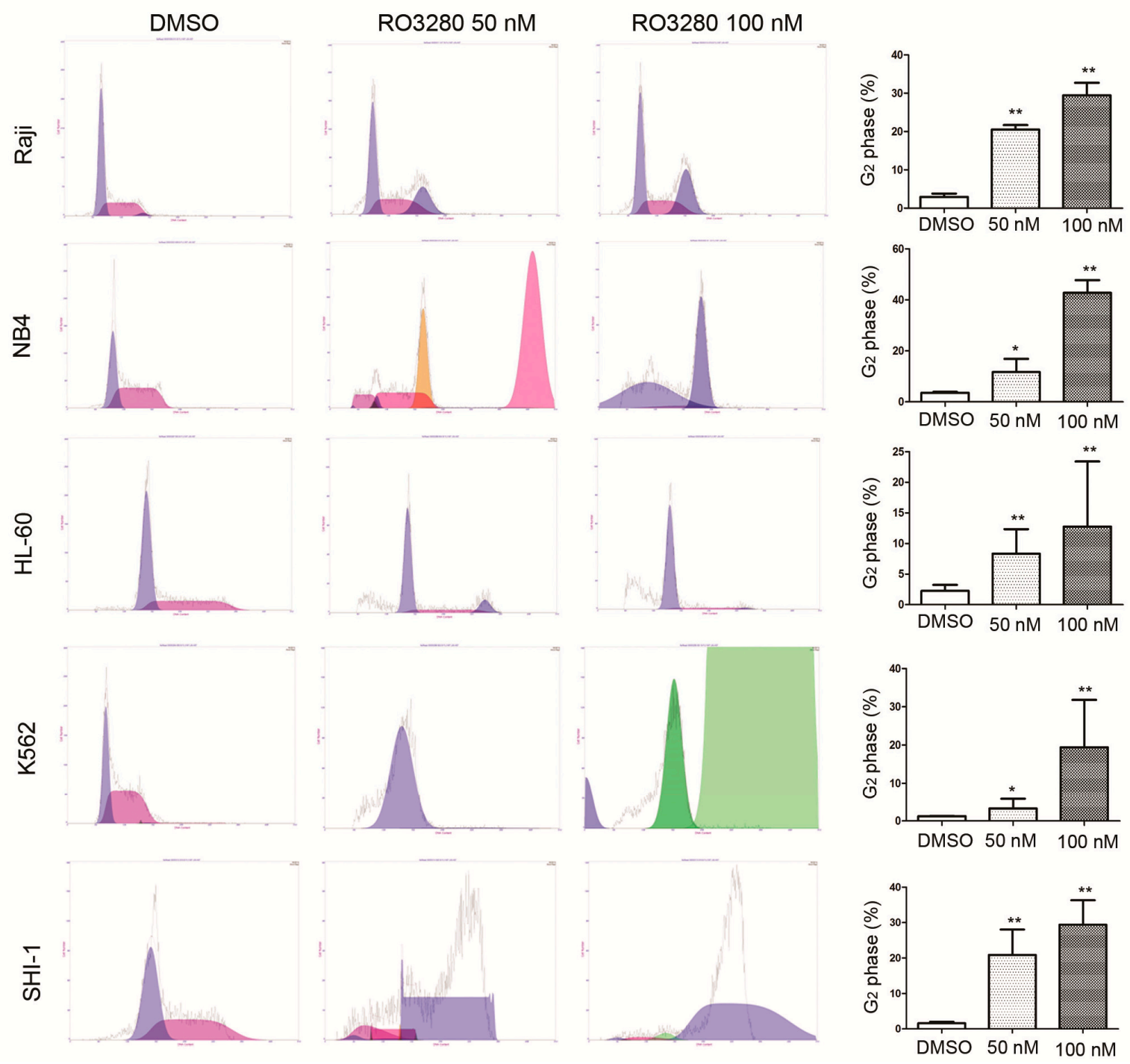

Figure 4. Cont. 

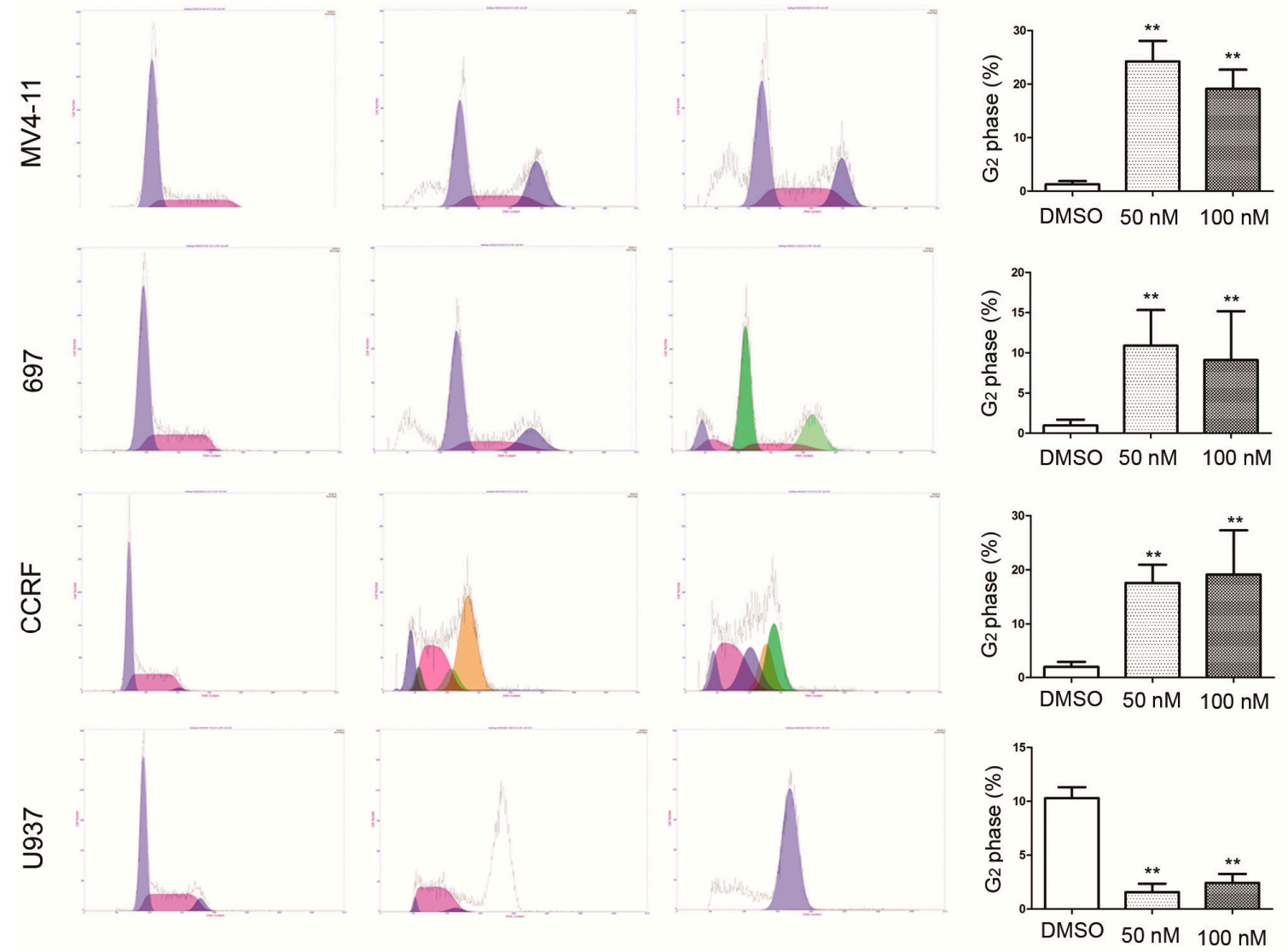

Figure 4. Cell cycle analysis of RO3280 induced cell cycle disorder in acute leukemia cells. Cell cycle analysis of nine leukemia cells treated for $24 \mathrm{~h}$ with RO3280 at 50 or $100 \mathrm{nM}$ compared with DMSO control mock treatment. $\mathrm{G}_{2}$ phase of each group was analyzed and presented. All these analyses were repeated three times. ${ }^{*} p<0.05 ; * * p<0.01$. Left purple peak mean the $\mathrm{G}_{1}$ phase and right purple peak mean the $\mathrm{G}_{2}$ phase, red peak means the $\mathrm{S}$ phase; Pink, yellow and green peak mean the disorder of cell cycle.

A
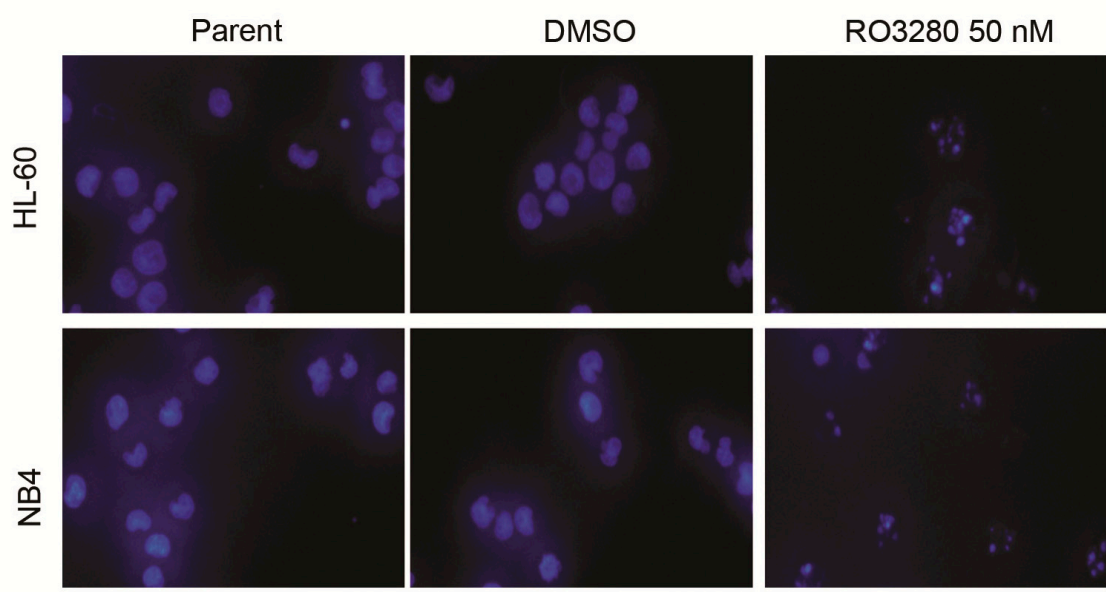

RO3280 $100 \mathrm{nM}$
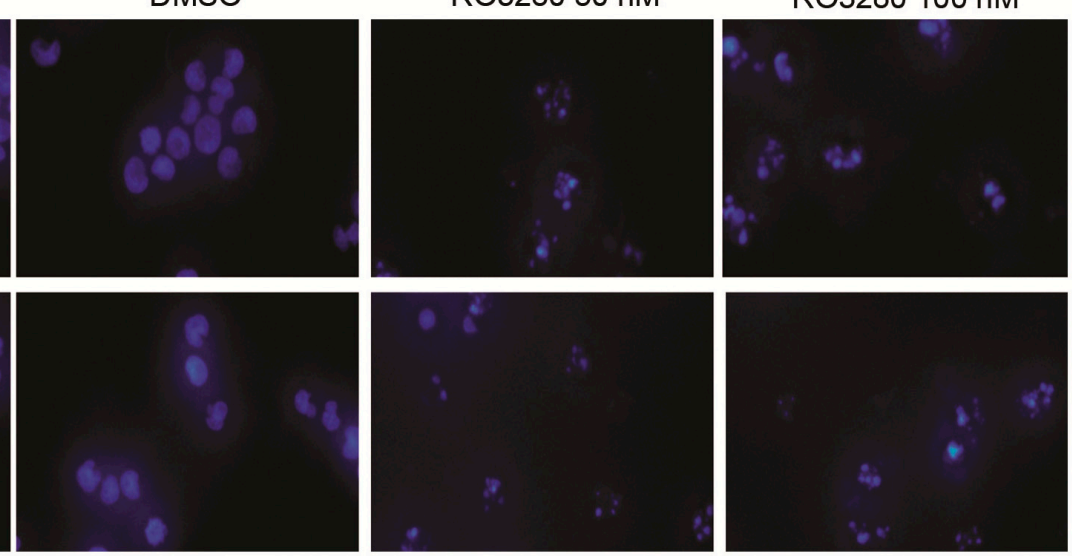

Figure 5. Cont. 
$\mathrm{B}$
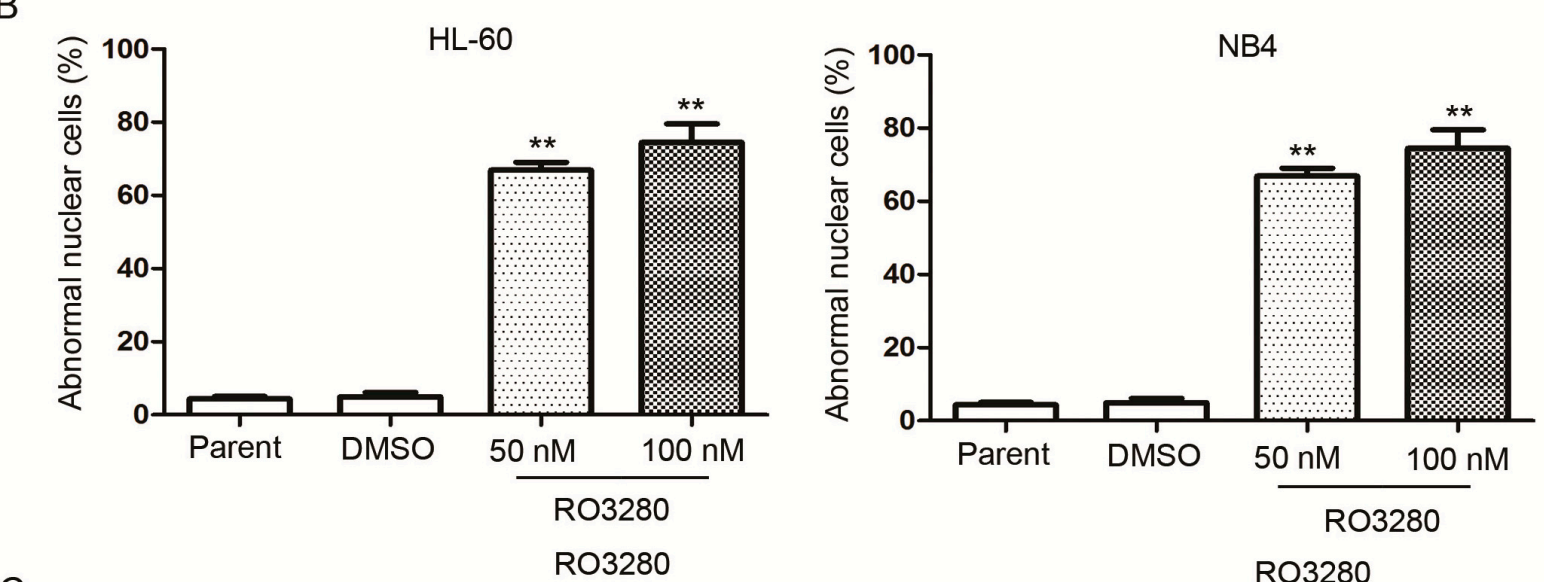

C

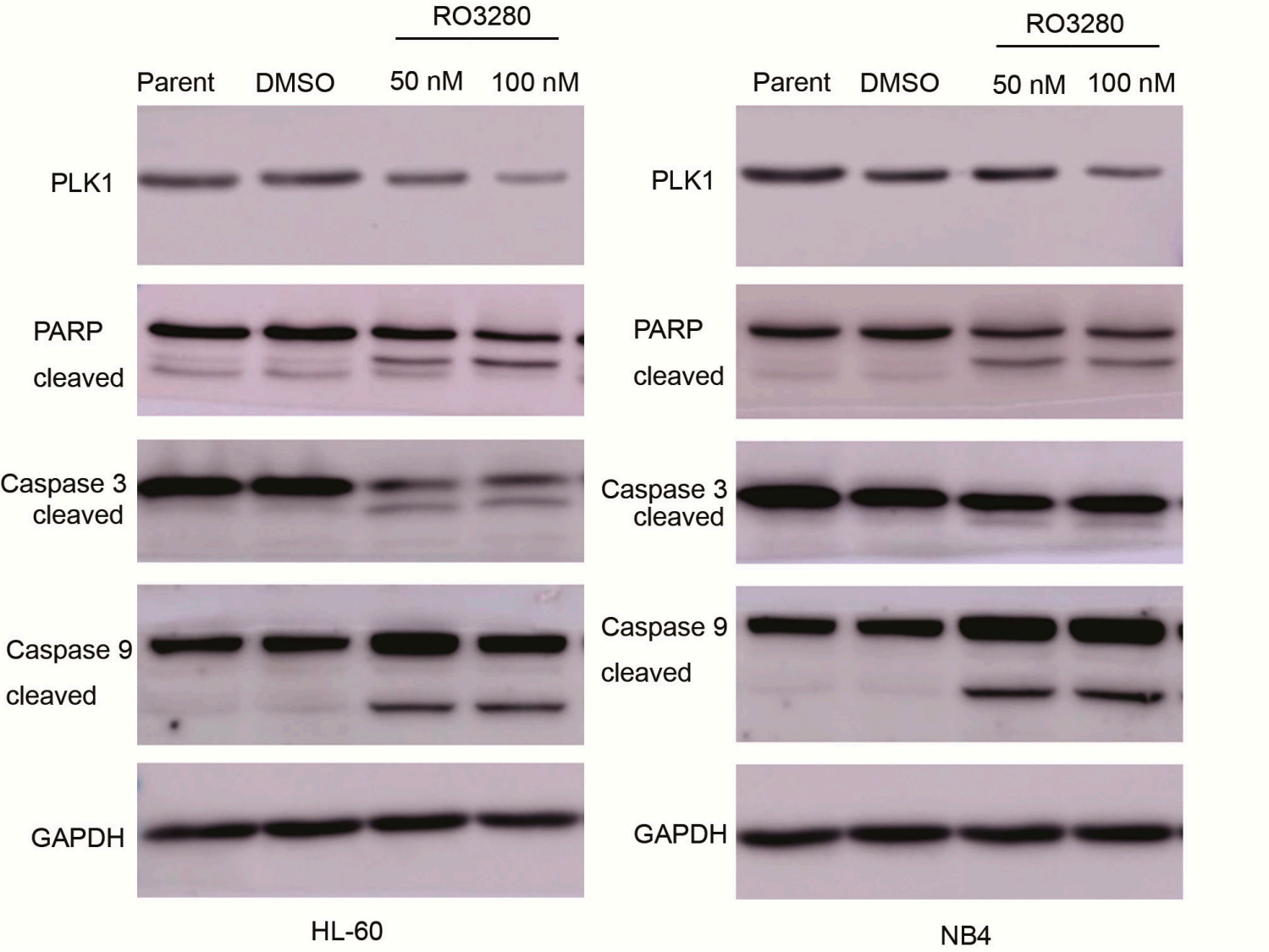

Figure 5. RO3280 induced DNA fragmentation and cleavage of apoptotic markers in acute leukemia cells. (A) Micrographs following Hoechst 33342 staining of cells treated with RO3280 (50 and $100 \mathrm{nM}$ ) for $24 \mathrm{~h}$. This demonstrates the induction of DNA fragmentation and abnormal nuclear cell formation; (B) The abnormal nuclear cells were quantified and increased significantly with RO3280 treatment compared with mock treatment in both HL-60 and NB4 cells. ** $p<0.01$; and (C) Western blot analysis of PARP, caspase-3, and caspase-9. After $24 \mathrm{~h}$ treatment with 50 or $100 \mathrm{nM}$ RO3280, cleaved PARP and caspase-9 were detected in lysates from NB4 and HL-60 cells.

\subsection{Real-Time PCR Array Identifies Genes Implicated in the Effect of RO3280 Treatment}

In order to identify apoptosis and/or programmed cell death molecules implicated in the effects of RO3280, we used the SABioscience Human Apoptosis PCR Array PAHS-3012. With this real-time 
PCR array we analyzed and clustered the expression of 370 genes associated with apoptosis in DMSO or RO3280 treated cells (Figure 6A). The genes most significantly upregulated or downregulated are shown in Figure 6B,C, respectively. Examination of the array data revealed that 32 genes were significantly upregulated and 16 genes were significantly downregulated in RO3280 treatment group compared with DMSO control group (Tables 6 and 7, respectively). The upregulated genes included protein kinase $\mathrm{C}$ zeta, receptor-interacting serine-threonine kinase 3, harakiri BCL2 interacting protein, DCC netrin 1 receptor, and cyclin-dependent kinase inhibitor $1 \mathrm{~A}$. The downregulated genes included interleukin $1 \alpha$, nucleotide-binding oligomerization domain containing 2 , caspase-1, apoptosis-related cysteine peptidase, serpin peptidase inhibitor clade B, B-cell CLL/lymphoma 2, and Bruton agammaglobulinemia tyrosine kinase. The RO3280-dependent upregulation of DCC and CDKN1A and downregulation of BTK and SOCS2 was verified by western blot analysis (Figure 7).

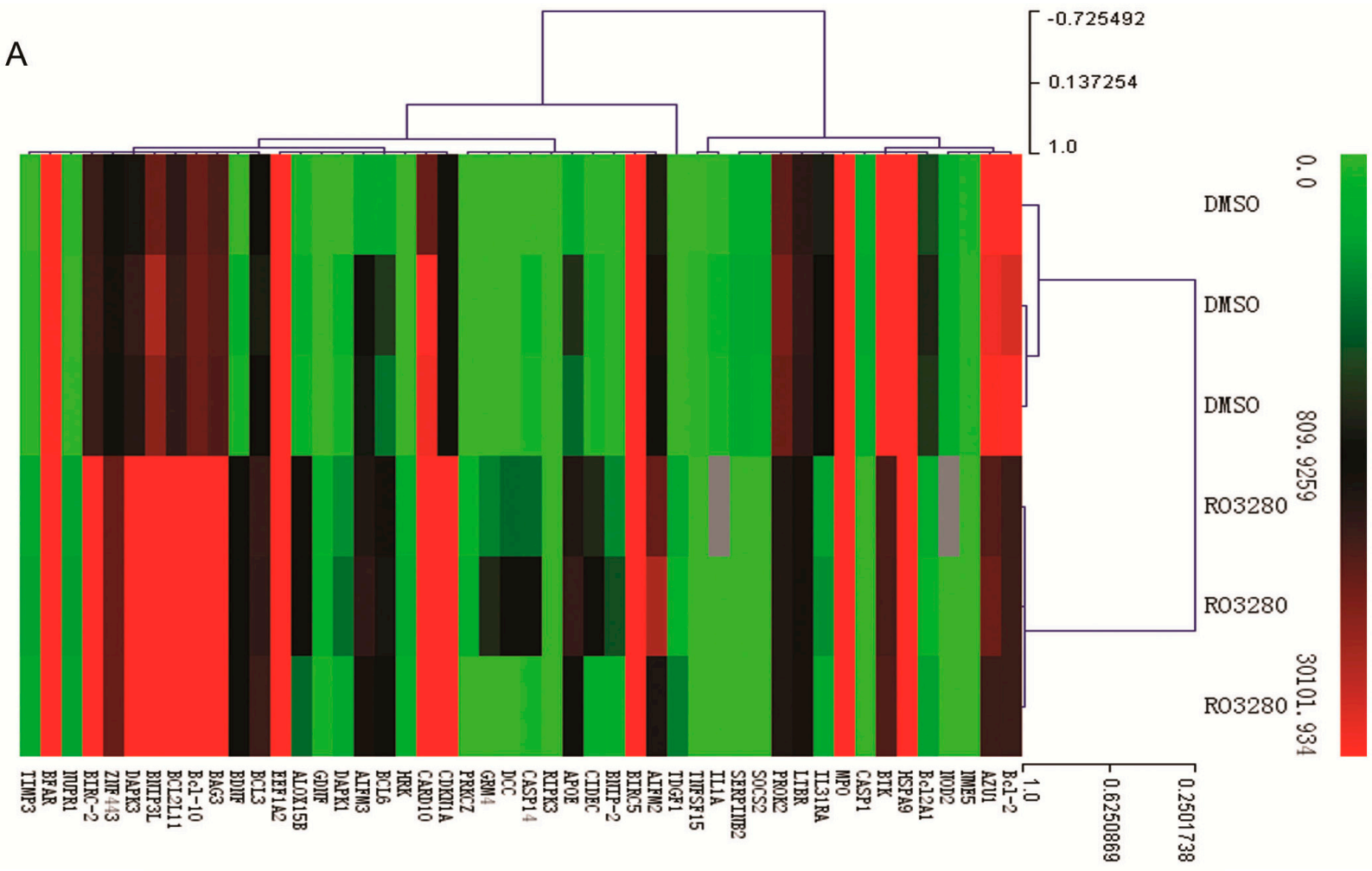

B

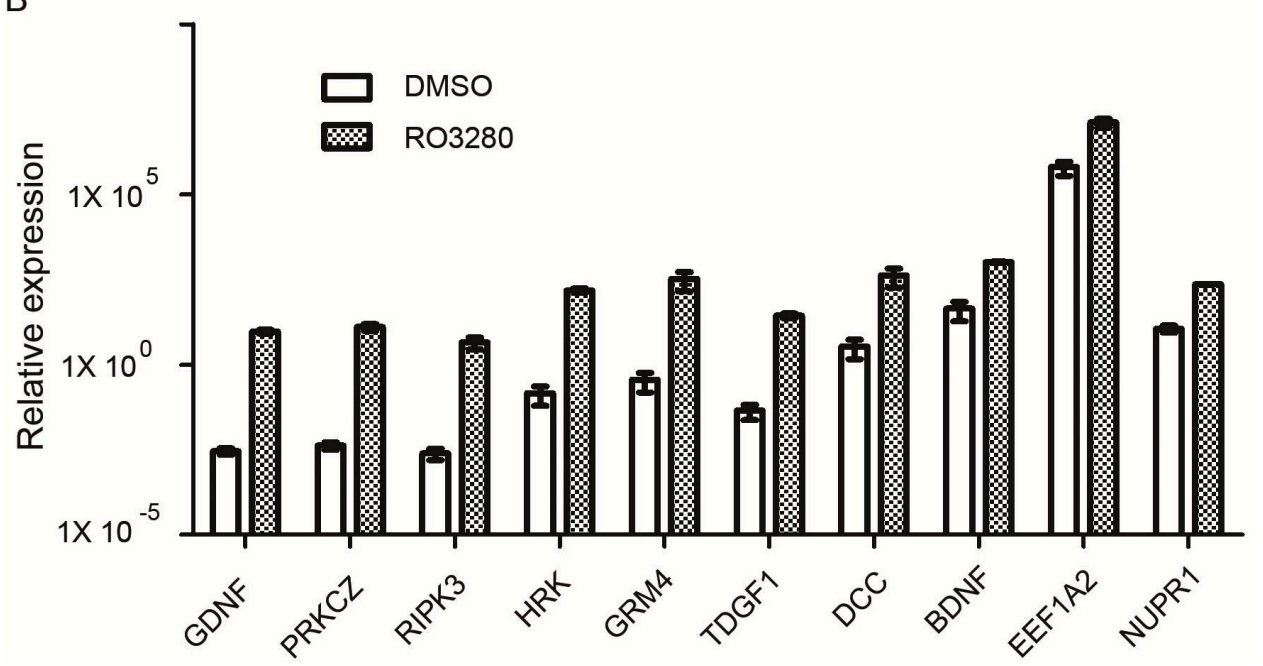

Figure 6. Cont. 


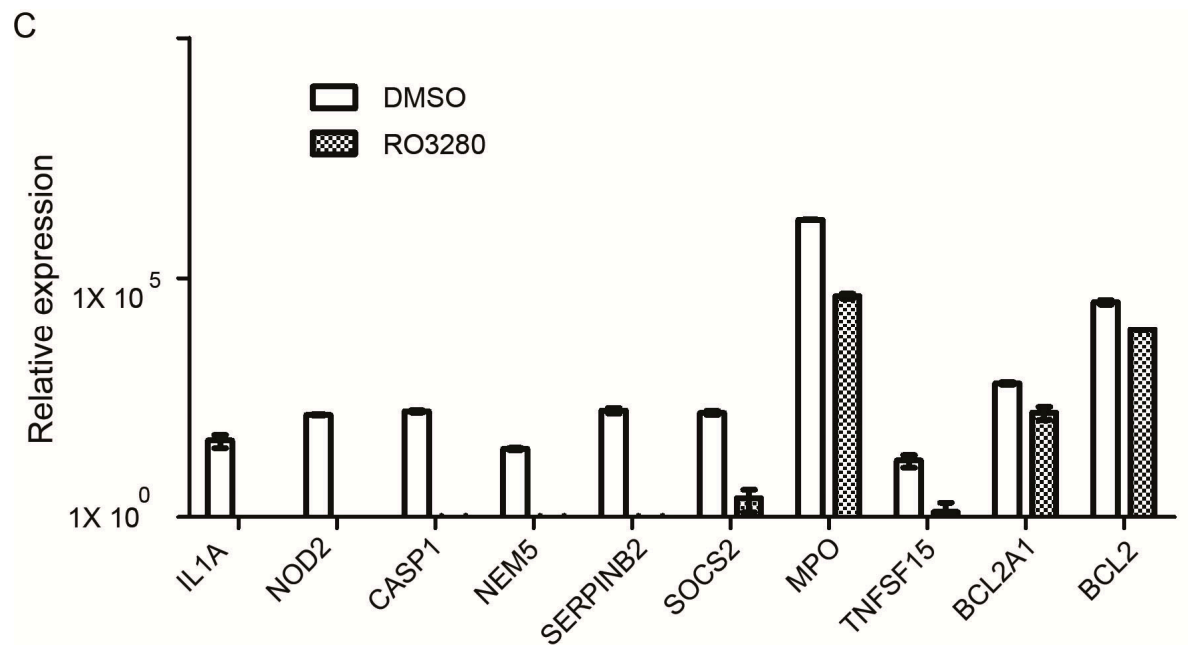

Figure 6. Real-time PCR array identifies genes implicated in the effect of RO3280 treatment. (A) Gene expression clustering of 370 key apoptosis genes in $50 \mathrm{nM}$ RO3280-treated NB4 cells compared to DMSO-treated cells; (B) Relative expression of the most upregulated genes in RO3280-treated NB4 cells compared to DMSO-treated cells; and (C) Relative expression of the most downregulated genes in RO3280-treated NB4 cells compared to DMSO-treated cells.
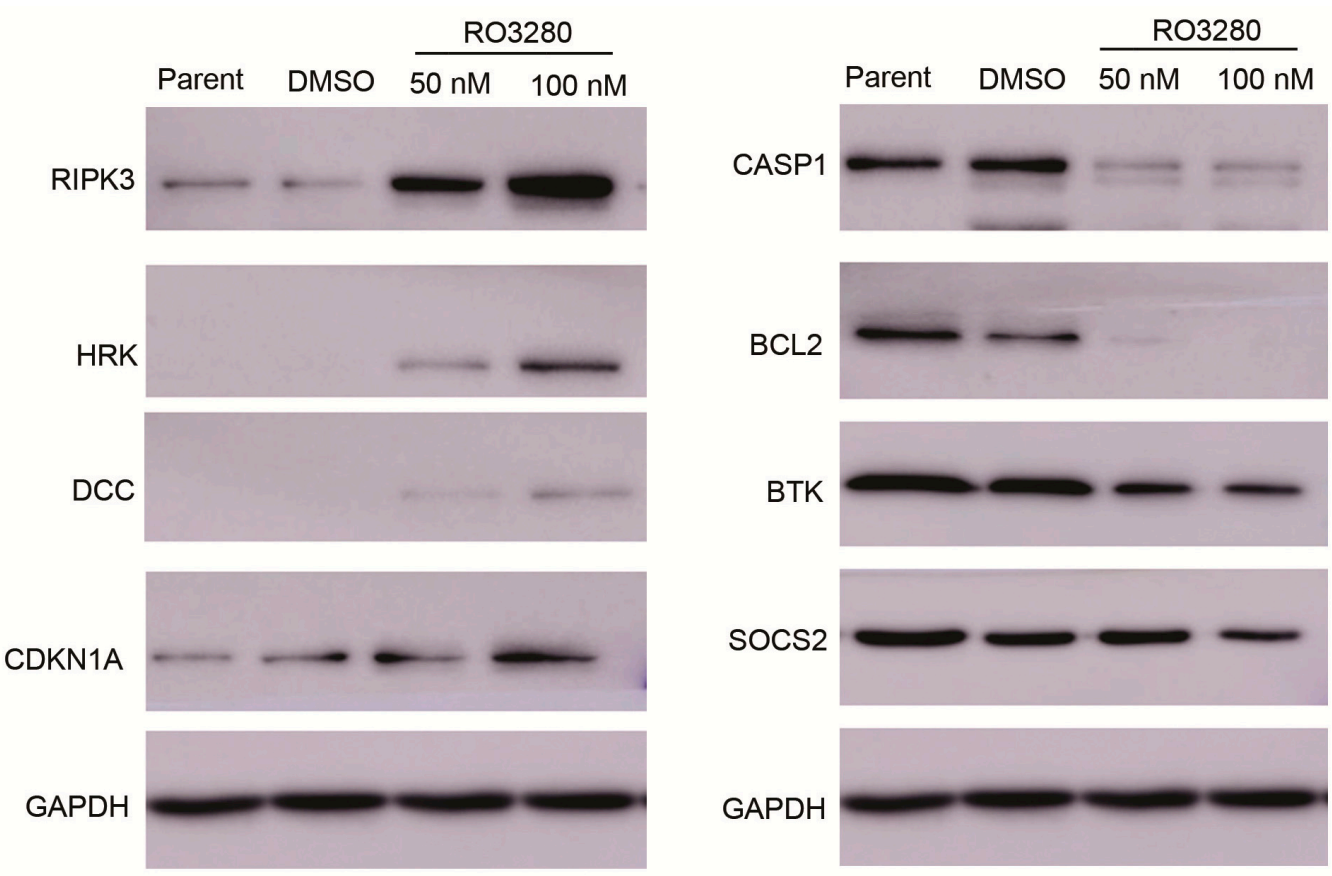

Figure 7. Western blot verification of real-time PCR array results. Western blot analysis of cells following a $24 \mathrm{~h}$ treatment with RO3280 at 50 or $100 \mathrm{nM}$ compared with DMSO control mock treatment. The upregulation of DCC and CDKN1A and down regulation of BTK and SOCS2 in RO3280 treated cells. Protein lysates from treated cells were tested for expression levels by Western blot analysis. 
Table 6. Genes upregulated in NB4 cells treated with RO3280 compared with the DMSO control group.

\begin{tabular}{|c|c|c|c|c|c|}
\hline Gene & Description & DMSO & RO3280 & Fold Change & $p$ Value \\
\hline$G D N F$ & glial cell derived neurotrophic factor & 0.0029 & 9.4172 & 3262.8632 & 0.0162 \\
\hline PRKCZ & protein kinase $\mathrm{C}$, zeta & 0.0042 & 12.7679 & 3065.9848 & 0.0457 \\
\hline RIPK3 & receptor-interacting serine-threonine kinase 3 & 0.0025 & 4.5249 & 1802.2433 & 0.0126 \\
\hline$H R K$ & harakiri, BCL2 interacting protein & 0.1471 & 150.6503 & 1023.9242 & 0.0246 \\
\hline GRM4 & glutamate receptor, metabotropic 4 & 0.3625 & 335.0571 & 924.1889 & 0.0225 \\
\hline$T D G F 1$ & teratocarcinoma-derived growth factor 1 & 0.0451 & 27.3203 & 605.1673 & 0.0218 \\
\hline$D C C$ & DCC netrin 1 receptor & 3.4002 & 425.7855 & 125.2247 & 0.0225 \\
\hline$B D N F$ & brain-derived neurotrophic factor & 44.1739 & 1023.2023 & 23.1630 & 0.0007 \\
\hline EEF1A2 & eukaryotic translation elongation factor $1 \alpha 2$ & $633,377.6354$ & $12,905,456.2968$ & 20.3756 & 0.0083 \\
\hline NUPR1 & nuclear protein, transcriptional regulator, 1 & 11.4562 & 232.1343 & 20.2629 & 0.0001 \\
\hline CIDEC & cell death-inducing DFFA-like effector c & 33.4482 & 667.6981 & 19.9621 & 0.0187 \\
\hline CDKN1A & cyclin-dependent kinase inhibitor $1 \mathrm{~A}$ & 2113.7362 & $36,484.2997$ & 17.2606 & 0.0113 \\
\hline$B N I P-2$ & BCL2/adenovirus E1B $19 \mathrm{kDa}$ interacting protein 2 & 18.2415 & 306.7483 & 16.8160 & 0.0145 \\
\hline BIRC5 & baculoviral IAP repeat containing 5 & $60,340.7297$ & $981,719.5648$ & 16.2696 & 0.0164 \\
\hline TIMP3 & TIMP metallopeptidase inhibitor 3 & 15.1670 & 201.9090 & 13.3124 & 0.0031 \\
\hline CASP14 & caspase 14 , apoptosis-related cysteine peptidase & 32.1570 & 410.5166 & 12.7660 & 0.0226 \\
\hline CARD10 & caspase recruitment domain family, member 10 & $28,245.9365$ & $329,683.7209$ & 11.6719 & 0.0292 \\
\hline$A L O X 15 B$ & arachidonate 15 -lipoxygenase, type $\mathrm{B}$ & 68.4589 & 796.1735 & 11.6299 & 0.0488 \\
\hline$A P O E$ & apolipoprotein E & 411.8114 & 4632.2654 & 11.2485 & 0.0119 \\
\hline$B C L 3$ & B-cell CLL/lymphoma 3 & 950.2097 & 7763.8336 & 8.1707 & 0.0013 \\
\hline$B N I P 3 L$ & BCL2/adenovirus E1B $19 \mathrm{kDa}$ interacting protein 3-like & $16,818.9831$ & $130,854.4287$ & 7.7802 & 0.0001 \\
\hline$D A P K 1$ & death-associated protein kinase 1 & 40.6424 & 287.7947 & 7.0811 & 0.0050 \\
\hline AIFM2 & apoptosis-inducing factor, mitochondrion-associated, 2 & 1759.5718 & $12,454.0471$ & 7.0779 & 0.0156 \\
\hline BCL6 & B-cell CLL/lymphoma 6 & 385.7559 & 2574.1201 & 6.6729 & 0.0061 \\
\hline AIFM3 & apoptosis-inducing factor, mitochondrion-associated, 3 & 764.9698 & 5057.6217 & 6.6115 & 0.0500 \\
\hline ZNF443 & zinc finger protein 443 & 2001.5333 & $12,744.6420$ & 6.3674 & 0.0009 \\
\hline$D A P K 3$ & death-associated protein kinase 3 & 5607.9528 & $30,206.6219$ & 5.3864 & 0.0020 \\
\hline$B C L 2 L 11$ & BCL2-like 11 (apoptosis facilitator) & 7094.6609 & $34,581.3650$ & 4.8743 & 0.0000 \\
\hline
\end{tabular}


Table 6. Cont.

\begin{tabular}{cccccc}
\hline Gene & Description & DMSO & RO3280 & Fold Change & $\boldsymbol{p}$ Value \\
\hline$B I R C-2$ & baculoviral IAP repeat containing 2 & 8366.5954 & $35,580.9121$ & 4.2527 & 0.0007 \\
$B A G 3$ & BCL2-associated athanogene 3 & $10,487.7923$ & $34,964.8259$ & 3.3339 & 0.0002 \\
$B c l-10$ & B-cell CLL/lymphoma 10 & $13,170.6013$ & $36,171.7865$ & 2.7464 & 0.0000 \\
$B F A R$ & bifunctional apoptosis regulator & $14,398.6434$ & $31,271.8562$ & 2.1719 & 0.0243 \\
\hline
\end{tabular}

Table 7. Genes downregulated in NB4 cells treated with RO3280 compared with the DMSO control group.

\begin{tabular}{cccccc}
\hline Gene & Description & DMSO & RO3280 & Fold Change & $\boldsymbol{p}$ Value \\
\hline IL1A & interleukin 1 $\alpha$ & 39.8703 & 0.0000 & 0.0000 & 0.0316 \\
NOD2 & nucleotide-binding oligomerization domain containing 2 & 135.5059 & 0.0000 & 0.0000 & 0.0000 \\
CASP1 & caspase 1, apoptosis-related cysteine peptidase & 161.0668 & 0.0011 & 0.0000 & 0.0001 \\
NME5 & NME/NM23 family member 5 & 26.4650 & 0.0006 & 0.0000 & 0.0000 \\
SERPINB2 & serpin peptidase inhibitor, clade B & 168.2487 & 0.2504 & 0.0015 & 0.001 \\
SOCS2 & suppressor of cytokine signaling 2 & 150.3483 & 2.5012 & 0.0166 & 0.0006 \\
MPO & myeloperoxidase & $1,652,217.4204$ & $42,599.1776$ & 0.0258 & 0.0000 \\
TNFSF15 & tumor necrosis factor superfamily, member 15 & 15.2009 & 1.2803 & 0.0842 & 0.0360 \\
Bcl2A1 & BCL2-related protein A1 & 619.9195 & 152.6633 & 0.2463 & 0.0019 \\
Bcl-2 & B-cell CLL/lymphoma 2 & $31,688.9516$ & 8210.5905 & 0.2591 & 0.0026 \\
BTK & Bruton's agammaglobulinemia tyrosine kinase & $37,873.9816$ & 9837.2022 & 0.2597 & 0.0001 \\
$I L 31 R A$ & interleukin 31 receptor A & 823.6783 & 230.4415 & 0.2798 & 0.0009 \\
PROK2 & prokineticin 2 & $13,280.3733$ & 4801.4889 & 0.3615 & 0.0004 \\
AZU1 & azurocidin 1 & $29,361.9342$ & $10,755.3769$ & 0.3663 & 0.0003 \\
LTBR & lymphotoxin $\beta$ receptor & 6702.9536 & 2753.6837 & 0.4108 & 0.0004 \\
$H S P A 9$ & heat shock 70 kDa protein 9 & $318,280.1754$ & $141,258.3887$ & 0.4438 & 0.0000 \\
\hline
\end{tabular}


Serine/threonine-protein kinase PLK1, also known as polo-like kinase 1 (PLK-1) or serine/threonine-protein kinase 13 (STPK13). PLK1 is an early trigger for G2/M transition. PLK1 supports the functional maturation of the centrosome in late $\mathrm{G}_{2} /$ early prophase and establishment of the bipolar spindle. PLK1 is an interesting molecule both as a biomarker and as a target for highly specific cancer therapy for several reasons. Firstly, it is over-expressed in many cancers and can serve as a biomarker. PLK1 is highly expressed in a broad range of tumors. Secondly, the expression of PLK1 in untransformed cells is not nearly as high, which makes it a discriminating target for the development of cancer-specific small molecule drugs. Medical experts are now paying more attention to the role of PLK1 in acute myeloid leukemia [35]. Here we show that PLK1 is highly expressed in all AML cell lines tested and in $73.3 \%(11 / 15)$ of the pediatric AML samples compared to $0 \%(0 / 12)$ of the NBM control sample. Real-time PCR analysis of 105 pediatric AML samples demonstrated significantly upregulated PLK1 expression in the AML samples compared to the control samples. Sometimes the results of the RT-PCR were not very accurate when the cDNA quality of samples was not very high. Thus, it is best to utilize Western blot analysis in future studies. Kaplan-Meier survival analysis of 105 pediatric AML patients revealed shorter survival time correlated with high PLK1 expression in tumors. Furthermore, multivariate analysis revealed that PLK1 expression is an independent prognostic factor in pediatric AML. In summary, our results are indicate for the first time that PLK1 may be a good oncogene target in samples from pediatric AML patients and human myeloid leukemia cell lines.

Several PLK1 inhibitors have been discovered and show significant anticancer effects. ATP-competitive inhibitor BI 6727 [36,37] is currently in clinical trials for cancer treatment. PLK1 inhibition with BI2536 leads to apoptotic effects in SCCHN cell lines [38]. BI2536 is a potent PLK1 inhibitor with $\mathrm{IC}_{50}$ of $0.83 \mathrm{nM}$. BI2536 also shows 4 - and 11-fold greater selectivity against PLK2 and PLK3, and its effects in leukemia have been reported by others [32]. TAK-960 is currently undergoing Phase I evaluation in adult patients with advanced solid malignancies [39]. ON 01910. Na inhibits mitotic progression and induces apoptosis in most cancer cell lines [40], is currently in a phase I study for treating adult patients with advanced solid malignancies [41]. Rigosertib (ON-01910) is a PLK1 inhibitor with $\mathrm{IC}_{50}$ of $9 \mathrm{nM}$. As presented here, in leukemia cells, RO3280 is more effective than Rigosertib (ON-01910). Wovkulich and colleagues recently developed RO3280, a novel PLK1 inhibitor [30]. RO3280 is a potent, highly selective inhibitor of PLK1 with IC50 of $3 \mathrm{nM}$. Until now, we know that PLK1 is a target of RO3280 and RO3280 has nearly no effect on PLK2 and PLK3. However, the effectiveness of RO3280 in leukemia treatment remains an open question. In this report we demonstrate that RO3280 inhibits leukemia cell proliferation in a dose-dependent manner and causes apoptosis. This suggests that RO3280 may be a promising antitumor treatment for leukemia. Indeed the potential of PLK1 inhibitors in treatment is promising, and combinations of PLK1 inhibitors with other anticancer drugs might offer a larger range of opportunities for cancer therapy [42].

Real-time PCR Array System is ideal tool for analyzing the expression of a focused panel of genes [43]. In this study, we used real-time PCR arrays to analyze the effect of RO3280 treatment on apoptotic gene regulation. Compared to an untreated control group, 32 genes related to apoptosis were significantly upregulated and 16 genes were significantly downregulated after RO3280 treatment. This confirmed previous reports that CDKN1A, CASP1, and BCL2 are regulated by PLK1 inhibition. PLK1 is a checkpoint protein whose role spans all of mitosis and includes DNA repair. PLK1 has been reported as a negative regulator of CDKN1A (p21) [44]. When cancer cells are treated with PLK1 
inhibitors, p21 is increased in the cytoplasm. By contrast, deficiency of p21 renders tumor cells more susceptible to Polo-like kinase 1 inhibition [45]. A rrecent study showed that PLK1 inhibition causes post-mitotic DNA damage and senescence in a range of human tumor cell lines [46]. Small-molecule PLK1 inhibitors and PLK1 genetic knock-down resulted in the induction of DNA double-strand breaks and senescence in a range of human tumor cell lines. Molecular function of PLK1 is very complicated and in metastatic alveolar rhabdomyosarcoma (aRMS), PLK1 interacted with and phosphorylated PAX3-FOXO1 leading to protein stabilization. PLK1 inhibition led to elevated ubiquitination and rapid proteasomal degradation of this PAX3-FOXO1 chimeric oncoprotein [47]. Our study also identified some novel genes such as RIPK3, HRK, DCC, and BTK regulated by PLK1 inhibition. While each of these genes has a function related to apoptosis, many are additionally involved in separate cellular processes. RIPK3 is a component of the tumor necrosis factor (TNF) receptor-I signaling complex and a key regulator of TNF-induced necrosis [48]. The DCC gene encodes a netrin 1 receptor that partially localizes to lipid rafts and induces apoptosis in the absence of ligand. The receptor functions as a tumor suppressor and is frequently mutated or down regulated in colorectal [49] and ovarian cancers [50]. HRK promotes apoptosis in mammalian cells by interacting with the apoptotic inhibitors BCL-2 and BCL-X $\mathrm{X}_{\mathrm{L}}$ via its $\mathrm{BH} 3$ domain [51]. Recent research indicates that PLK1 is an important regulator of PTEN during cell cycle progression [52]. Our research now indicates that PLK1 may also regulate RIPK3, DCC, and HRK expression. Until now, the regulation mechanism of PLK1 is still unclear. Thus, our results may provide new clues into the molecular mechanism of apoptosis induced by RO3280 in leukemia cells.

\section{Experimental Section}

\subsection{Cell and Culture Conditions}

Leukemia cell lines HL-60, MV4-11, U937, DAMI and K562 were obtained from the American Type Culture Collection (ATCC, Manassas, VA, USA). CCRF, Raji, Jurkat, 697 and SHI-1 cell lines (gifts from Wang Jian-Rong, The Cyrus Tang Hematology center of Soochow University, Suzhou, China). All cell lines were maintained at $37{ }^{\circ} \mathrm{C}$ in RPMI 1640 (Gibco, Carlsbad, CA, USA) supplemented with 10\% fetal bovine serum (Invitrogen, Carlsbad, CA, USA). RO3280 (Cat: S7248; Selleck Chemicals, West Paterson, NJ, USA) was dissolved in DMSO (Cat: D4540; Sigma-Aldrich, St. Louis, MO, USA).

\subsection{Patients and Samples}

Bone marrow specimens were obtained from 105 pediatric patients with AML at the time of diagnosis, who presented at Children's Hospital of Soochow University between 2000 and 2011. Ethical approval was provided by the Children's Hospital of Soochow University Ethics Committee (Nos. SUEC2000-021 and SUEC2011-037), and written informed consent was obtained from the parents or guardians. AML diagnosis was made in accordance with the revised French-American-British (FAB) classification. Patients' clinical and laboratory features are summarized in Table 1. Additionally, 23 healthy donors' bone marrow samples and seven patients with ITP were analyzed as controls. 
Bone marrow mononuclear cells (BMNCs) from patients were isolated within $2 \mathrm{~h}$ using Ficoll solution when bone marrow samples were harvested.

\subsection{CD34+ Cell Purification}

For CD34+ cell selection, the Miltenyi immunoaffinity device (VarioMACS 130-046-703) was used according to the manufacturer's instructions (Miltenyi Biotech, Auburn, CA, USA). Briefly, the CD34+ cells are magnetically labeled with CD34 MicroBeads. Then, the cell suspension is loaded onto a MACSR column which is placed in the magnetic field of a MACS Separator. The magnetically labeled CD34+ cells are retained within the column. The unlabeled cells run through; CD34+ cells were adsorbed on the magnetic poles. After removing the column from the magnetic field, the magnetically retained CD34+ cells can be eluted as the positively selected cell fraction.

\subsection{Quantitative Reverse-Transcription PCR for PLK1}

Quantitative real-time PCR was performed to determine the expression levels of PLK1 genes. Total RNA was reverse transcribed using the Reverse Transcription Kit, according to the manufacturer's protocol (Applied Biosystems Inc., Foster City, CA, USA). The real time PCR primers used to quantify GAPDH expression were: Forward (F): 5'-AGAAGGCTGGGGCTCATTTG-3' and Reverse (R): 5'-AG GGGCCATCCACAGTCTTC-3' and for PLK1 were: F: 5'-AGTCGACCACCTCACCTGTC-3' and R: 5'-GCCCCTCACAGTCCTCAATA-3'. Expression of PLK1 was normalized to endogenous GAPDH expression. Real-time PCR array analysis was according to the MIQE Guidelines [53] and performed in a total volume of $20 \mu \mathrm{L}$ including $1 \mu \mathrm{L}$ of cDNA, primers $(0.2 \mathrm{mM}$ each) and $10 \mu \mathrm{L}$ of SYBR Green mix (Roche, Basel, Switzerland). Reactions were run on a Lightcycler 480 (Roche) using universal thermal cycling parameters $\left(95^{\circ} \mathrm{C}\right.$ for $5 \mathrm{~min}, 45$ cycles of $10 \mathrm{~s}$ at $95^{\circ} \mathrm{C}, 20 \mathrm{~s}$ at $60{ }^{\circ} \mathrm{C}$ and $15 \mathrm{~s}$ at $72{ }^{\circ} \mathrm{C}$; followed by a melting curve: $10 \mathrm{~s}$ at $95{ }^{\circ} \mathrm{C}, 60 \mathrm{~s}$ at $60{ }^{\circ} \mathrm{C}$ and continued melting). The results were obtained using the sequence detection software of the Lightcycler 480 and analyzed using Microsoft Excel. For quality control purposes, melting curves were acquired for all samples. The comparative $C_{\mathrm{t}}$ method was used to quantify gene expression. The target gene expression level was normalized to expression of the housekeeping gene glyceraldehyde 3-phosphate dehydrogenase (GAPDH) within the same sample $\left(-\Delta C_{\mathrm{t}}\right)$, and then the relative expression of each gene was calculated using $\log 2\left(-\Delta C_{\mathrm{t}}\right)$.

\subsection{Cell Proliferation and Viability Assay}

Leukemia cells or primary leukemia cells $\left(2 \times 10^{4}\right)$ were seeded in 96-well plates overnight and incubated with DMSO, or increasing concentrations of RO3280 $(0.05-120 \mu \mathrm{M})$ for $24 \mathrm{~h}$. The same volume of DMSO added to the vehicle treated wells. Each drug concentration was replicated four times. Then, $10 \mu \mathrm{L}$ CCK8 (Dojindo Molecular Technologies, Tokyo, Japan) solution was added to each well, incubated at $37{ }^{\circ} \mathrm{C}$ for $2-4 \mathrm{~h}$ and the optical density (OD) values were measured at $450 \mathrm{~nm}$ using a scanning multi-well spectrophotometer (BioRad Model 550, Hercules, CA, USA). Relative survival rate was calculated from the absorbance values compared with the control group. The proliferation of cells was calculated as a percentage of the DMSO-treated control wells with 50\% inhibitory concentration ( $\mathrm{IC}_{50}$ ) values derived after plotting proliferation values on a logarithmic curve. 
The IC 50 of PLK1 inhibitor was calculated by Graph Prism software (GraphPad-Prism Software Inc., San Diego, CA, USA).

\subsection{Cell Cycle Analysis}

Firstly, leukemia cells were collected and washed with PBS for $5 \mathrm{~min}$ by centrifugation at $125 \times \mathrm{g}$. Then, cells were fixed with paraformaldehyde and transparented with $0.5 \%$ Triton $\mathrm{X}-100$ for 10 min. After that, cells were resuspended and incubated for $30 \mathrm{~min}$ at $37{ }^{\circ} \mathrm{C}$ in staining solution containing $1.5 \mu \mathrm{mol} / \mathrm{L}$ propidium iodide (P4170; Sigma-Aldrich, St. Louis, MO, USA) and $25 \mu \mathrm{g} / \mathrm{mL}$ RNase A The samples $\left(1 \times 10^{4}\right.$ cells) were analyzed with a Beckman Gallios ${ }^{\mathrm{TM}}$ Flow Cytometer (Beckman, Krefeld, Germany).

\subsection{Apoptosis Assay}

Apoptosis assay was according to the manual operation of BD Annexin V Staining Kit (Cat: 556420; BD Biosciences, Franklin Lakes, NJ, USA). Briefly, cells were washed two times with cold PBS and then cells were resuspended in $1 \times$ Binding Buffer at a concentration of $\sim 1 \times 10^{6}$ cells $/ \mathrm{mL}$. Then $100 \mu \mathrm{L}$ of the solution $\left(\sim 1 \times 10^{5}\right.$ cells $)$ was transferred to a $5 \mathrm{~mL}$ culture tube. Annexin V and PI (Propidium Iodide) $5 \mu \mathrm{L} /$ test was added. Cells were gently mixed and incubated for 15 min at RT in the dark. $400 \mu \mathrm{L}$ of $1 \times$ Binding Buffer was added to each tube and the cells were analyzed by flow cytometry within one hour.

\subsection{Western Blot Analysis}

Cellular proteins were extracted in $40 \mathrm{mM}$ Tris- $\mathrm{HCl}(\mathrm{pH} 7.4)$ containing $150 \mathrm{mM} \mathrm{NaCl}$ and $1 \%(v / v)$ Triton $\mathrm{X}-100$, supplemented with protease inhibitors for western blot analysis. Equal amounts of protein were resolved on $12 \%$ SDS-PAGE gels, and then transferred to a PVDF membrane (Millipore, Bedford, MA, USA). Blots were blocked and probed with antibodies against Caspase 3 (Cat: 9661S, 1:1000; Cell Signaling Technology Inc., Danvers, MA, USA), Caspase 9 (Cat: 4501S 1:1000, Cell Signaling Technology Inc.), PARP (Cat: 9542S, 1:1000; Cell Signaling Technology Inc.), PLK1 (Cat: 4535S, 1:1000; Cell Signaling Technology Inc.), RIPK3 (Cat: 13526S,1:1000; Cell Signaling Technology Inc.), HRK (Cat: ab45419, 1:1000; Abcam Trading (Shanghai) Company Ltd., Shanghai, China), DCC (Cat: 3858S, 1:1000; Cell Signaling Technology Inc.), CDKN1A(Cat: 2947S, 1:1000; Cell Signaling Technology Inc.), CASP1 (Cat: 2225S, 1:1000; Cell Signaling Technology Inc.), BCL2 (Cat: ab7973, 1:1000; Abcam Trading (Shanghai) Company Ltd.), BTK(Cat: 3533S, 1:1000; Cell Signaling Technology Inc.), SOCS2 (Cat: 2779S, 1:1000; Cell Signaling Technology Inc.), GAPDH (1:5000; Sigma). After washing three times, the blots were incubated with horseradish peroxidase-conjugated secondary antibodies for $1 \mathrm{~h}$ and visualized using an enhanced chemiluminescence kit (Pierce, Rockford, IL, USA). Finally, the protein bands were visualized after exposure of the membrane to Kodak X-ray film (Kodak, Rochester, NY, USA). 


\subsection{Hoechst 33342 Staining Analysis}

Cells were seeded into 6-well plates, and then treated with RO3280 (50 or $100 \mathrm{nM}$ ) and cultured at $37{ }^{\circ} \mathrm{C}$ for $24 \mathrm{~h}$, stained with $0.1 \mu \mathrm{g} / \mathrm{mL}$ Hoechst 33342 (Sigma) for $5 \mathrm{~min}$, then observed with filters for blue fluorescence under fluorescence microscopy (OLYMPUS IX71; Olympus Corporation, Tokyo, Japan). Abnormal nuclear cells were counted between the RO3280 treatment group and DMSO control group.

\subsection{Real-Time PCR Array Analysis}

Samples from each group were submerged in $2 \mathrm{~mL}$ Trizol (Invitrogen) for RNA extraction, and stored at $-80{ }^{\circ} \mathrm{C}$ until further processed. cDNA synthesis was performed on $4 \mu \mathrm{g}$ of RNA in a $10 \mu \mathrm{L}$ sample volume using SuperScript II reverse transcriptase (Invitrogen) as recommended by the manufacturer. Real-time PCR array (SABioscience Human Apoptosis PCR Array PAHS-3012, Frederick, MD, USA) analysis was performed in a total volume of $20 \mu \mathrm{L}$ including $2 \mu \mathrm{L}$ of cDNA, primers $(0.2 \mathrm{mM}$ each) and $10 \mu \mathrm{L}$ of SYBR Green mix (Roche). For gene expression quantification a comparative $C_{\mathrm{t}}$ method was used. Gene expression levels for each sample were normalized to the expression level of the housekeeping gene encoding Glyceraldehyde 3-phosphate dehydrogenase $(\mathrm{GAPDH})$ within a given sample $\left(-\Delta C_{\mathrm{t}}\right)$; the relative expression of each gene was calculated with $10^{6} \times \log 2\left(-\Delta C_{\mathrm{t}}\right)$. Statistical significance of gene expression was calculated with the $t$-test using SPSS 11.5 software (Chicago, IL, USA).

\subsection{Statistical Analysis}

Each experimental condition was performed three times, and these replicates were presented in results. All values are presented as means \pm SEM. Student's paired $t$-test was applied to reveal statistical significances. $p$ values less than 0.05 were considered significant. Statistical analyses were performed using SPSS Software for Windows.

\section{Conclusions}

In this study, we identified PLK1 as a possible oncoprotein target in pediatric AML patient samples and human myeloid leukemia cell lines. Kaplan-Meier survival analysis revealed shorter survival time correlated with high PLK1 expression in tumors. Our findings also showed for the first time that RO3280 treatment inhibits cell proliferation and induces apoptosis in leukemia cells. Real time PCR array analysis demonstrated that 32 genes are significantly upregulated and 16 genes are significantly downregulated after RO3280 treatment. This is the first indication of RIPK3,HRK, DCC, and BTK gene regulation reported with $\mathrm{RO} 3280$ treatment. These results may provide new insights into the molecular mechanism of RO3280-induced apoptosis; however, further research will be required to determine the underlying details. Taken together, our findings suggest that RO3280 may be a suitable drug candidate for the treatment of pediatric AML. 


\section{Acknowledgments}

This work was supported by grants from the National Key Basic Research Program (No. 2010CB933902), grants from key medical subjects of Jiangsu province (XK201120), Innovative team of Jiangsu Province (Nos. LJ201114 and LJ201126), Special Clinical Medical Science and Technology of Jiangsu province (BL2012050, BL2013014), Key Laboratory of Suzhou (SZS201108, SZS201307), National Natural Science Foundation (Nos. 81100371, 81370627, 81300423 and 81272143), Natural Science Foundation of Jiangsu Province (No. BK2011308), Universities Natural Science Foundation of Jiangsu Province (No. 11KJB320014), Talent's Subsidy Project in Science and Education of the Department of Public Health of Suzhou City (No. SWKQ1020) and Major Scientific and Technological Special Project for "Significant New Drugs Creation” (No. 2012ZX09103301-040).

\section{Author Contributions}

Jian Pan and Xing Feng designed and directed the study; Na-Na Wang, Zhi-Heng Li and He Zhao performed most of the experiments; Yan-Fang Tao and Li-Xiao Xu performed the real-time PCR array analysis; Jun Lu, Wen-Li Zhao and Lan Cao collected the leukemia sample; Pei-Fang Xiao, Yi-Ping Li and Yun-Yun $\mathrm{Xu}$ collected the clinical information of samples; Xiao-Juan Du and Li-Chao Sun supported the design of primers for PCR; Fang Fang, Gang Li, Guang-Hao Su, Hui-Ting Zhou and Yan-Hong Li drafted the manuscript; Yi Wu, Mei-Fang Jin, Lin Liu and Xue-Ming Zhu performed the apoptosis analysis; Jian Wang, Shao-Yan Hu and Jian Ni participated in study design and coordination, data analysis and interpretation, and drafted the manuscript; and all authors read and approved the final manuscript.

\section{Conflicts of Interest}

The authors declare no conflict of interest.

\section{References}

1. Jemal, A.; Thomas, A.; Murray, T.; Thun, M. Cancer statistics. CA Cancer J. Clin. 2002, 52, 23-47.

2. Jabbour, E.; Cortes, J.; Ravandi, F.; O’Brien, S.; Kantarjian, H. Targeted therapies in hematology and their impact on patient care: Chronic and acute myeloid leukemia. Semin. Hematol. 2013, 50, 271-283.

3. Miano, M.; Micalizzi, C.; Calvillo, M.; Dufour, C. New targets in pediatric acute myeloid leukemia. Immunol. Lett. 2013, 155, 47-50.

4. Zhao, Y.; Huang, H.; Wei, G. Novel agents and biomarkers for acute lymphoid leukemia. J. Hematol. Oncol. 2013, 6, 40.

5. Moore, A.S.; Kearns, P.R.; Knapper, S.; Pearson, A.D.; Zwaan, C.M. Novel therapies for children with acute myeloid leukaemia. Leukemia 2013, 27, 1451-1460.

6. Lancet, J.E. New agents: Great expectations not realized. Best Pract. Res. Clin. Haematol. 2013, 26, 269-274.

7. Ostronoff, F.; Estey, E. The role of quizartinib in the treatment of acute myeloid leukemia. Expert Opin. Investig. Drugs 2013, 22, 1659-1669. 
8. Hales, E.C.; Taub, J.W.; Matherly, L.H. New insights into Notch1 regulation of the PI3K-AKT-mTOR1 signaling axis: Targeted therapy of gamma-secretase inhibitor resistant T-cell acute lymphoblastic leukemia. Cell. Signal. 2014, 26, 149-161.

9. Vitagliano, O.; Addeo, R.; D’Angelo, V.; Indolfi, C.; Indolfi, P.; Casale, F. The Bcl-2/Bax and Ras/Raf/MEK/ERK signaling pathways: Implications in pediatric leukemia pathogenesis and new prospects for therapeutic approaches. Expert Rev. Hematol. 2013, 6, 587-597.

10. Peloquin, G.L.; Chen, Y.B.; Fathi, A.T. The evolving landscape in the therapy of acute myeloid leukemia. Protein Cell 2013, 4, 735-746.

11. Smith, C.C.; Shah, N.P. The role of kinase inhibitors in the treatment of patients with acute myeloid leukemia. Am. Soc. Clin. Oncol. Educ. Book 2013, doi:10.1200/EdBook_AM.2013.33.313.

12. Hatzimichael, E.; Georgiou, G.; Benetatos, L.; Briasoulis, E. Gene mutations and molecularly targeted therapies in acute myeloid leukemia. Am. J. Blood Res. 2013, 3, $29-51$.

13. Gjertsen, B.T.; Schoffski, P. Discovery and development of the Polo-like kinase inhibitor volasertib in cancer therapy. Leukemia 2014, doi:10.1038/leu.2014.222.

14. Tsykunova, G.; Reikvam, H.; Ahmed, A.B.; Nepstad, I.; Gjertsen, B.T.; Bruserud, O. Targeting of polo-like kinases and their cross talk with Aurora kinases-Possible therapeutic strategies in human acute myeloid leukemia? Expert Opin. Investig. Drugs 2012, 21, 587-603.

15. Wasch, R.; Hasskarl, J.; Schnerch, D.; Lubbert, M. BI2536-Targeting the mitotic kinase Polo-like kinase 1 (PLK1). In Small Molecules in Oncology; Springer Berlin Heidelberg: Berlin, Germany, 2010; Volume 184, pp. 215-218.

16. Zhang, Z.; Zhang, G.; Kong, C. High expression of Polo-like kinase 1 is associated with the metastasis and recurrence in urothelial carcinoma of bladder. Urol. Oncol. 2013, 31, 1222-1230.

17. Zhang, G.; Zhang, Z.; Liu, Z. Polo-like kinase 1 is overexpressed in renal cancer and participates in the proliferation and invasion of renal cancer cells. Tumour Biol. 2013, 34, 1887-1894.

18. Maire, V.; Nemati, F.; Richardson, M.; Vincent-Salomon, A.; Tesson, B.; Rigaill, G.; Gravier, E.; Marty-Prouvost, B.; de Koning, L.; Lang, G.; et al. Polo-like kinase 1: A potential therapeutic option in combination with conventional chemotherapy for the management of patients with triple-negative breast cancer. Cancer Res. 2013, 73, 813-823.

19. Deeraksa, A.; Pan, J.; Sha, Y.; Liu, X.D.; Eissa, N.T.; Lin, S.H.; Yu-Lee, L.Y. PLK1 is upregulated in androgen-insensitive prostate cancer cells and its inhibition leads to necroptosis. Oncogene 2013, 32, 2973-2983.

20. Ackermann, S.; Goeser, F.; Schulte, J.H.; Schramm, A.; Ehemann, V.; Hero, B.; Eggert, A.; Berthold, F.; Fischer, M. Polo-like kinase 1 is a therapeutic target in high-risk neuroblastoma. Clin. Cancer Res. 2011, 17, 731-741.

21. Pellegrino, R.; Calvisi, D.F.; Ladu, S.; Ehemann, V.; Staniscia, T.; Evert, M.; Dombrowski, F.; Schirmacher, P.; Longerich, T. Oncogenic and tumor suppressive roles of Polo-like kinases in human hepatocellular carcinoma. Hepatology 2010, 51, 857-868.

22. Zhang, Y.; Liu, Y.; Yang, Y.X.; Xia, J.H.; Zhang, H.X.; Li, H.B.; Yu, C.Z. The expression of PLK-1 in cervical carcinoma: A possible target for enhancing chemosensitivity. J. Exp. Clin. Cancer Res. 2009, 28, 130.

23. Schmit, T.L.; Zhong, W.; Nihal, M.; Ahmad, N. Polo-like kinase 1 (PLK1) in non-melanoma skin cancers. Cell Cycle 2009, 8, 2697-2702. 
24. Renner, A.G.; Dos Santos, C.; Recher, C.; Bailly, C.; Creancier, L.; Kruczynski, A.; Payrastre, B.; Manenti, S. Polo-like kinase 1 is overexpressed in acute myeloid leukemia and its inhibition preferentially targets the proliferation of leukemic cells. Blood 2009, 114, 659-662.

25. Zhang, Y.; Du, X.L.; Wang, C.J.; Lin, D.C.; Ruan, X.; Feng, Y.B.; Huo, Y.Q.; Peng, H.; Cui, J.L.; Zhang, T.T.; et al. Reciprocal activation between PLK1 and STAT3 contributes to survival and proliferation of esophageal cancer cells. Gastroenterology 2012, 142, 521-530.

26. Behren, A.; Muhlen, S.; Acuna Sanhueza, G.A.; Schwager, C.; Plinkert, P.K.; Huber, P.E.; Abdollahi, A.; Simon, C. Phenotype-assisted transcriptome analysis identifies FOXM1 downstream from Ras-MKK3-p38 to regulate in vitro cellular invasion. Oncogene 2010, 29, 1519-1530.

27. Malumbres, M. Preclinical models for cell cycle-targeted therapies. Adv. Exp. Med. Biol. 2006, 587, 139-147.

28. Valsasina, B.; Beria, I.; Alli, C.; Alzani, R.; Avanzi, N.; Ballinari, D.; Cappella, P.; Caruso, M.; Casolaro, A.; Ciavolella, A.; et al. NMS-P937, an orally available, specific small-molecule Polo-like kinase 1 inhibitor with antitumor activity in solid and hematologic malignancies. Mol. Cancer Ther. 2012, 11, 1006-1016.

29. Hikichi, Y.; Honda, K.; Hikami, K.; Miyashita, H.; Kaieda, I.; Murai, S.; Uchiyama, N.; Hasegawa, M.; Kawamoto, T.; Sato, T.; et al. TAK-960, a novel, orally available, selective inhibitor of Polo-like kinase 1, shows broad-spectrum preclinical antitumor activity in multiple dosing regimens. Mol. Cancer Ther. 2012, 11, 700-709.

30. Chen, S.; Bartkovitz, D.; Cai, J.; Chen, Y.; Chen, Z.; Chu, X.J.; Le, K.; Le, N.T.; Luk, K.C.; Mischke, S.; et al. Identification of novel, potent and selective inhibitors of Polo-like kinase 1. Bioorgan. Med. Chem. Lett. 2012, 22, 1247-1250.

31. Gumireddy, K.; Reddy, M.V.; Cosenza, S.C.; Boominathan, R.; Baker, S.J.; Papathi, N.; Jiang, J.; Holland, J.; Reddy, E.P. ON01910, a non-ATP-competitive small molecule inhibitor of PLK1, is a potent anticancer agent. Cancer Cell 2005, 7, 275-286.

32. Oliveira, J.C.; Pezuk, J.A.; Brassesco, M.S.; Morales, A.G.; Queiroz, R.G.; Scrideli, C.A.; Tone, L.G. PLK1 expression and BI2536 effects in childhood acute lymphoblastic leukemia. Pediatr. Blood Cancer 2014, 61, 1227-1231.

33. Dasmahapatra, G.; Patel, H.; Nguyen, T.; Attkisson, E.; Grant, S. PLK1 inhibitors synergistically potentiate HDAC inhibitor lethality in imatinib mesylate-sensitive or resistant BCR/ABL+ leukemia cells in vitro and in vivo. Clin. Cancer Res. 2013, 19, 404-414.

34. Ikezoe, T.; Yang, J.; Nishioka, C.; Takezaki, Y.; Tasaka, T.; Togitani, K.; Koeffler, H.P.; Yokoyama, A. A novel treatment strategy targeting Polo-like kinase 1 in hematological malignancies. Leukemia 2009, 23, 1564-1576.

35. Berg, T.; Bug, G.; Ottmann, O.G.; Strebhardt, K. Polo-like kinases in AML. Expert Opin. Investig. Drugs 2012, 21, 1069-1074.

36. Stadler, W.M.; Vaughn, D.J.; Sonpavde, G.; Vogelzang, N.J.; Tagawa, S.T.; Petrylak, D.P.; Rosen, P.; Lin, C.C.; Mahoney, J.; Modi, S.; et al. An open-label, single-arm, phase 2 trial of the Polo-like kinase inhibitor volasertib (BI6727) in patients with locally advanced or metastatic urothelial cancer. Cancer 2014, 120, 976-982. 
37. Lin, C.C.; Su, W.C.; Yen, C.J.; Hsu, C.H.; Su, W.P.; Yeh, K.H.; Lu, Y.S.; Cheng, A.L.; Huang, D.C.; Fritsch, H.; et al. A phase I study of two dosing schedules of volasertib (BI6727), an intravenous Polo-like kinase inhibitor, in patients with advanced solid malignancies. Br. J. Cancer 2014, 110, 2434-2440.

38. Wagenblast, J.; Hirth, D.; Thron, L.; Arnoldner, C.; Diensthuber, M.; Stover, T.; Hambek, M. Effects of the Polo-like-kinase-1-inhibitor BI2536 in squamous cell carcinoma cell lines of the head and neck. Oncol. Lett. 2012, 4, 175-177.

39. Nie, Z.; Feher, V.; Natala, S.; McBride, C.; Kiryanov, A.; Jones, B.; Lam, B.; Liu, Y.; Kaldor, S.; Stafford, J.; et al. Discovery of TAK-960: An orally available small molecule inhibitor of Polo-like kinase 1 (PLK1). Bioorg. Med. Chem. Lett. 2013, 23, 3662-3666.

40. Oussenko, I.A.; Holland, J.F.; Reddy, E.P.; Ohnuma, T. Effect of ON 01910. Na, an anticancer mitotic inhibitor, on cell-cycle progression correlates with RanGAP1 hyperphosphorylation. Cancer Res. 2011, 71, 4968-4976.

41. Bowles, D.W.; Diamond, J.R.; Lam, E.T.; Weekes, C.D.; Astling, D.P.; Anderson, R.T.; Leong, S.; Gore, L.; Varella-Garcia, M.; Vogler, B.W.; et al. Phase I study of oral rigosertib (ON 01910. Na), a dual inhibitor of the PI3K and PLK1 pathways, in adult patients with advanced solid malignancies. Clin. Cancer Res. 2014, 20, 1656-1665.

42. Garuti, L.; Roberti, M.; Bottegoni, G. Polo-like kinases inhibitors. Curr. Med. Chem. 2012, 19, 3937-3948.

43. Schmittgen, T.D.; Lee, E.J.; Jiang, J. High-throughput real-time PCR. Methods Mol. Biol. 2008, 429, 89-98.

44. Liu, X. PLK1, a negative regulator of p21. Cell Cycle 2009, 8, 336-337.

45. Kreis, N.N.; Louwen, F.; Zimmer, B.; Yuan, J. Loss of p21Cip1/CDKN1A renders cancer cells susceptible to Polo-like kinase 1 inhibition. Oncotarget 2014, in press.

46. Driscoll, D.L.; Chakravarty, A.; Bowman, D.; Shinde, V.; Lasky, K.; Shi, J.; Vos, T.; Stringer, B.; Amidon, B.; D'Amore, N.; et al. PLK1 inhibition causes post-mitotic DNA damage and senescence in a range of human tumor cell lines. PLoS One 2014, 9, e111060.

47. Thalhammer, V.; Lopez-Garcia, L.A.; Herrero Martin, D.; Hecker, R.; Laubscher, D.; Gierisch, M.E.; Wachtel, M.; Bode, P.; Nanni, P.; Blank, B.; et al. PLK1 phosphorylates PAX3-FOXO1 the inhibition of which triggers regression of alveolar rhabdomyosarcoma. Cancer Res. 2014, doi:10.1158/0008-5472.

48. Zhao, J.; Jitkaew, S.; Cai, Z.; Choksi, S.; Li, Q.; Luo, J.; Liu, Z.G. Mixed lineage kinase domain-like is a key receptor interacting protein 3 downstream component of TNF-induced necrosis. Proc. Natl. Acad. Sci. USA 2012, 109, 5322-5327.

49. Haddick, P.C.; Tom, I.; Luis, E.; Quinones, G.; Wranik, B.J.; Ramani, S.R.; Stephan, J.P.; Tessier-Lavigne, M.; Gonzalez, L.C. Defining the ligand specificity of the deleted in colorectal cancer (DCC) receptor. PLoS One 2014, 9, e84823.

50. Meimei, L.; Peiling, L.; Baoxin, L.; Changmin, L.; Rujin, Z.; Chunjie, H. Lost expression of DCC gene in ovarian cancer and its inhibition in ovarian cancer cells. Med. Oncol. 2011, 28, 282-289.

51. Inohara, N.; Ding, L.; Chen, S.; Nunez, G. harakiri, A novel regulator of cell death, encodes a protein that activates apoptosis and interacts selectively with survival-promoting proteins BCL-2 and BCL-X $\mathrm{L}_{\mathrm{L}}$ EMBO J. 1997, 16, 1686-1694. 
52. Choi, B.; Pagano, M.; Dai, W. PLK1 phosphorylates PTEN and regulates its mitotic activity during the cell cycle. J. Biol. Chem. 2014, 20, 14066-14074.

53. Bustin, S.A.; Benes, V.; Garson, J.A.; Hellemans, J.; Huggett, J.; Kubista, M.; Mueller, R.; Nolan, T.; Pfaffl, M.W.; Shipley, G.L.; et al. The MIQE guidelines: Minimum information for publication of quantitative real-time PCR experiments. Clin. Chem. 2009, 55, 611-622.

(C) 2015 by the authors; licensee MDPI, Basel, Switzerland. This article is an open access article distributed under the terms and conditions of the Creative Commons Attribution license (http://creativecommons.org/licenses/by/4.0/). 